\title{
Ginsenosides as anticancer agents: in vitro and in vivo activities, structure-activity relationships, and molecular mechanisms of action
}

\author{
Subhasree Ashok Nag ${ }^{1}$, Jiang-Jiang Qin ${ }^{1}$, Wei Wang ${ }^{1,2}$, Ming-Hai Wang ${ }^{2,3}$, Hui Wang ${ }^{4}$ and Ruiwen Zhang ${ }^{1,2 *}$ \\ Department of Pharmaceutical Sciences, Texas Tech University Health Sciences Center, Amarillo, TX, USA \\ ${ }^{2}$ Cancer Biology Center, School of Pharmacy, Texas Tech University Health Sciences Center, Amarillo, TX, USA \\ ${ }^{3}$ Department of Biomedical Sciences, School of Pharmacy, Texas Tech University Health Sciences Center, Amarillo, TX, USA \\ ${ }^{4}$ Institute for Nutritional Sciences, Shanghai Institutes for Biological Sciences, Chinese Academy of Sciences, Shanghai, China
}

\section{Edited by:}

Wei-Dong Zhang, Second Military

Medical University, China

Reviewed by:

Yi Feng, Shanghai University of

Traditional Chinese Medicine, China

Zhenlin Hu, Second Military Medical

University, China

*Correspondence:

Ruiwen Zhang, Department of Pharmaceutical Sciences, Texas Tech University Health Sciences Center, 1300 South Coulter Street, Amarillo, TX 79106, USA.

e-mail: ruiwen.zhang@ttuhsc.edu
Conventional chemotherapeutic agents are often toxic not only to tumor cells but also to normal cells, limiting their therapeutic use in the clinic. Novel natural product anticancer compounds present an attractive alternative to synthetic compounds, based on their favorable safety and efficacy profiles. Several pre-clinical and clinical studies have demonstrated the anticancer potential of Panax ginseng, a widely used traditional Chinese medicine. The anti-tumor efficacy of ginseng is attributed mainly to the presence of saponins, known as ginsenosides. In this review, we focus on how ginsenosides exert their anticancer effects by modulation of diverse signaling pathways, including regulation of cell proliferation mediators (CDKs and cyclins), growth factors (c-myc, EGFR, and vascular endothelial growth factor), tumor suppressors (p53 and p21), oncogenes (MDM2), cell death mediators (Bcl2, Bcl-xL, XIAP, caspases, and death receptors), inflammatory response molecules (NF-kB and COX-2), and protein kinases (JNK, Akt, and AMP-activated protein kinase). We also discuss the structure-activity relationship of various ginsenosides and their potentials in the treatment of various human cancers. In summary, recent advances in the discovery and evaluation of ginsenosides as cancer therapeutic agents support further pre-clinical and clinical development of these agents for the treatment of primary and metastatic tumors.

Keywords: Panax genus, Panax ginseng, ginsenosides, anticancer activities, structure-activity relationship, molecular mechanism, pre-clinical pharmacology, clinical trials

\section{INTRODUCTION}

\section{A BRIEF HISTORY OF GINSENG AND GINSENG PRODUCTS}

Panax ginseng was discovered over 5000 years ago on the hills of Manchuria in China and since then held its place as a highly venerated medicinal plant in Traditional Chinese Medicine (Hemmerly, 1977). The ancient Chinese used it for various health benefits, ranging from overcoming fatigue to treating severe cardiac problems; ancient texts showed that ginseng was valued more than gold and was often reserved for treatment of royalty. The "Shennong Bencao Jing" written around 100 A.D. attributed longevity boosting properties to ginseng and stated that it was good for "enlightening the mind and increasing the wisdom" (Dharmananda, 2002).

The discovery of an American counterpart for this "miracle" plant happened in 1714, due to the efforts of Father Lafitau, a Jesuit priest, working with the Iroquois in Canada. Based on the theory that ginseng might grow wild in the Americas, due to a similarity in climactic conditions with China, Father Lafitau undertook a laborious search for the plant and eventually discovered that it was used as a medicinal herb by the native Indians too (Yun, 2001; Grafton, 2002). The British physicians F. Porter Smith and G. A. Stuart, working in China at the end of the nineteenth century, were among the first to introduce the medicinal qualities of this herb to a Western audience (Dharmananda, 2002). The popularity of ginseng in the western world grew as a "drug weary" population medicated heavily on increasingly toxic chemical compounds started to explore alternative and traditional forms of medicine. Ginseng began to be sold in the form of liquid extracts, capsules, chewing gum, teas, candy, and cigarettes. It was used for treating rheumatism, anemia, insomnia, and various other problems. Some even purchased ginseng products for their alleged aphrodisiac properties. Ginseng fragrances were incorporated in cosmetics and soaps. By 1980s an estimated five to six million Americans were routinely using ginseng products (Carlson, 1986). In fact, the sale of ginseng products in the United States alone was estimated to reach US $\$ 83$ million in 2010.

In the early 1970s, reports, primarily from China and Korea, started claiming that the herb stimulated protein synthesis, lowered blood sugar and cholesterol levels, regulated rate of metabolism, protected against stress, and could therefore reduce mortality. Asiatic ginseng from eastern Siberia was reportedly used by Soviet cosmonauts and Olympic team trainees to reduce fatigue (Carlson, 1986). During the same period, the Fromm Operation based in Wisconsin funded research on the possibility of using compounds from American ginseng in cancer research (Carlson, 1986). Since then, ginseng's usefulness in cancer has been shown by extensive 
pre-clinical and epidemiological studies (Attele et al., 1999; Court, 2000; Bespalov et al., 2001; Yoo et al., 2006). It is also demonstrated that prolonged oral administration of red ginseng extract (RGE) to rats dosed with a carcinogen such as DMBA, urethane, or aflatoxin B1, reduced the incidence and mass of tumors (Yun et al., 1983). Additionally, red ginseng has been shown to improve postoperative survival in patients with stage III gastric cancer (Suh et al., 2002). There is an increasing interest in developing ginseng products as anticancer agents, especially in combination therapy.

\section{ETHNOBOTANY}

The word Panax, first used by the Russian botanist Carl Anton Von Meyer, is derived from the Greek word meaning "all-healing" (Court, 2000). On the other hand, the English word ginseng is derived from the Chinese term "rénshen" which literally means "man root": a reference to the root's resemblance to the legs of a human. The Panax genus belongs to the family Araliaceae and consists of at least nine species, including $P$. ginseng (Asian ginseng), P. quinquefolium L. (Xiyangshen, American ginseng), P. notoginseng (Sanqi), and P. japonicas (Japanese ginseng; Lee and Zhao, 2009). Among them, $P$. ginseng is the most widely used ginseng and is indigenous to the Far East countries, most notably China and Korea. P. quinquefolium is indigenous to the United States and Canada (Lee and Zhao, 2009). Out of these, P. ginseng C. A. Meyer, P. quinquefolium $\mathrm{L}$, and P. notoginseng have been extensively investigated for their physiological and pharmacological effects on human body.

Ginseng is a perennial herb, $60-80 \mathrm{~cm}$ tall. Its root, often $5-6 \mathrm{~cm}$ long, is fleshy, bifurcate, aromatic, and grayish white to amber yellow. The surface of root is wrinkled and furrowed, and its taste is sweetish at first, with a somewhat bitter after taste. Ginseng stem is simple, erect, and deep red; its flower is pink; and its fruit, a small berry, is red. The leaves are compound, digitate, oval, and thin. There are a total of five leaflets and the three terminal leaflets are larger than the two lateral ones (Yun, 2001; Coates et al., 2005).

\section{CHEMICAL CONSTITUENTS OF PLANTS FROM THE GENUS PANAX}

In general, the active or inactive chemical entities obtained from ginseng species can be classified into four categories as follows.

\section{SAPONINS (OR SAPOGENIN GLYCOSIDES)}

Saponins are glycosides consisting of a sapogenin moiety, which may be a steroid or a triterpene, attached to one or more sugar moieties. Ginseng saponins are generally called ginsenosides and are the main active principals of ginseng. They are often used as a marker for the quality control of ginseng drugs and commercial products. For example, the ginsenoside Rf is unique to Asian ginseng while F11 is found exclusively in American ginseng. Thus the Rf/F11 ratio is used as a phytochemical marker to distinguish American ginseng from Asian ginseng (Li et al., 2000; Assinwe et al., 2003).

The basic structures of ginsenosides are similar, and most ginsenosides consist of a dammarane steroid nucleus with 17 carbon atoms arranged in four rings. Ginsenoside structures are first elucidated by the Shibata group, and named as $\mathrm{Rx}$ according to their mobility on TLC plates, with polarity decreasing from index "a" to "h" (Sanada et al., 1974; Liu and Xiao, 1992). According to a Ginseng Evaluation Program led by the American Botanical Council of Austin, Texas, the ginsenosides Rb1, Rb2, Rc, Rd, Re, and Rg1 account for $>90 \%$ of the total ginsenoside content of the $P$. ginseng root (Foster, 1996a,b; Chang et al., 2003). Whereas, ginsenosides Rb1, Re, Rd, Rc, Rg1, and Rb3, the six major saponins, make up more than $70 \%$ of total ginsenoside content in American ginseng (Wang et al., 2005). Ginsenosides are amphipathic in nature. The hydroxyl $(\mathrm{OH})$ group attached to the steroid backbone in ginsenosides allows interactions between the polar head of the membrane phospholipids and the $\beta-\mathrm{OH}$ group of cholesterol, while the hydrophobic steroid backbone can interact with the hydrophobic side chains of fatty acids and cholesterol. These physicochemical interactions are mostly determined by the numbers and sites of polar hydroxyl groups on each ginsenoside. Based on such properties, ginsenosides with different numbers and sites of hydroxyl groups exhibit diverse activities. Till date, more than 100 ginsenosides have been isolated from Panax species and most of them exhibit four types of aglycone moieties (Liu and Xiao, 1992; Coates et al., 2005). Ginsenosides are classified into the following types based on the steroidal skeleton and number of hydroxyl groups/sugar moieties attached.

\section{Protopanaxadiol}

Protopanaxadiols (PPD; Figure 1) belong to the dammarane-type ginsenosides, such as ginsenosides Ra1, Ra2, Ra3, Rb1, Rb2, and $\mathrm{Rb} 3$, notoginsenoside R1, R2, Rs1, and Rs2, quinquenoside R1, and malonylginsenoside $\mathrm{Rb} 1, \mathrm{Rb} 2, \mathrm{Rc}$, and $\mathrm{Rd}$ (Sanada et al., 1974; Kasai et al., 1983). More than 30 ginsenosides of the PPD type belong to the Rb series (Dharmananda, 2002). The metabolic pathway of the PPD-type ginsenosides has been extensively investigated, resulting in identification and characterization of several active metabolites, notably compound $\mathrm{K}$ (also referred to as compound M1 or IH-901; Hasegawa et al., 1996).

\section{Protopanaxatriol}

Protopanaxatriols (PPT; Figure 2) are also dammarane-type ginsenosides, including ginsenosides Re, Rf, Rg1, and notoginsenoside $\mathrm{R} 1$. The main structural difference between PPT and PPD is the presence of a hydroxyl group/sugar residue at C- 6 in the PPT moiety (Sanada et al., 1974; Kasai et al., 1983).

\section{Oleanolic acid (or aglycone oleanolic acid)}

This type, including ginsenosides Ro, has a pentacyclic triterpene skeleton (Figure 2).

\section{Ocotillol}

This group has a five-membered epoxy ring at C-20 (Figure 2; Nakamura et al., 2007). Majonoside R2 from the Vietnamese ginseng is a prototype for this group (Konoshima et al., 1999).

\section{POLYSACCHARIDES}

Ginseng polysaccharides are water-soluble compounds containing various sugar moieties conjugated to uronic acid and include panaxanes A to $\mathrm{U}$. They are acidic polysaccharides and have been shown to possess immunomodulating and anti-proliferative effects. Recent studies have identified an acidic polysaccharide, 


\section{Protopanaxadiol-type}

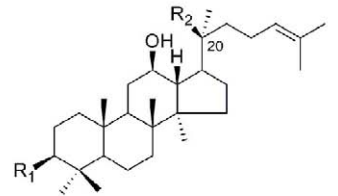

\begin{tabular}{|c|c|c|c|}
\hline & & $\mathrm{R}_{1}$ & $\mathrm{R}_{2}$ \\
\hline 1 & ginsenoside $\mathrm{Ra}_{1}$ & $-\mathrm{O}-\mathrm{glc} \mathrm{c}^{2}-^{1} \mathrm{glc}$ & $-O-g\left|c^{6}-{ }^{1} \operatorname{ara}(P)^{4}-{ }^{1} x y\right|$ \\
\hline 2 & ginsenoside $\mathrm{Ra}_{2}$ & 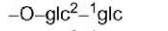 & $-O-g \mid c^{6}-{ }^{1}$ ara $(f)^{2}-{ }^{1} x y \mid$ \\
\hline 3 & ginsenoside $R b_{1}$ & $-\mathrm{O}-\mathrm{g} \mid \mathrm{c}^{2}-{ }^{1} \mathrm{glc}$ & $-0-g_{c}^{6}-^{1} g l c$ \\
\hline 4 & ginsenoside $R b_{2}$ & $-\mathrm{O}-\mathrm{glc}^{2}-1 \mathrm{glc}$ & $-\mathrm{O}-\mathrm{glc} \mathrm{c}^{6}-^{1} \operatorname{ara}(\mathrm{P})$ \\
\hline 5 & ginsenoside $\mathrm{Rb}_{3}$ & $-O-g\left|c^{2}-19\right| c$ & $-0-g\left|c^{2}-{ }^{1} x y\right|$ \\
\hline 6 & ginsenoside Rc & $-\mathrm{O}-\mathrm{glc}^{2}-{ }^{1} \mathrm{glc}$ & $-O-g l c^{2}-{ }^{1}$ ara $(f)$ \\
\hline 7 & ginsenoside $\mathrm{Rd}$ & $-\mathrm{O}-\mathrm{glc}^{2}-{ }^{1} \mathrm{glc}$ & $-\mathrm{O}-\mathrm{glc}$ \\
\hline 8 & (20S)-ginsenoside $\mathrm{Rg}_{3}$ & $-\mathrm{O}-\mathrm{glc} \mathrm{c}^{2}-{ }^{1} \mathrm{glc}$ & $\mathrm{OH}$ \\
\hline 9 & ginsenoside $\mathrm{Rh}_{2}$ & $-\mathrm{O}-\mathrm{glc}$ & $\mathrm{OH}$ \\
\hline 10 & ginsenoside $\mathrm{Rs}_{1}$ & $-\mathrm{O}-\mathrm{glc}^{2}-^{1} \mathrm{glc}^{6}-\mathrm{Ac}$ & $-0-g \mid c^{6}-{ }^{1} \operatorname{ara}(P)$ \\
\hline 11 & ginsenoside $\mathrm{Rs}_{2}$ & $-O-g \mid c^{2}-1{ }^{1} g c^{6}-A c$ & $-O-g l c^{6}-1$ ara $(f)$ \\
\hline 12 & quinquenoside $\mathrm{R}_{1}$ & $-O-g\left|c^{2}-{ }^{1} g\right| c^{6}-A c$ & $-0-g l c^{6}-{ }^{1} g l c$ \\
\hline 13 & compound $\mathrm{K}$ & $\mathrm{OH}$ & $-\mathrm{O}-\mathrm{glc}$ \\
\hline 14 & Chikusetsusaponin III & $\begin{array}{c}-0-g\left|c^{2}-{ }^{1} g\right| c \\
6 \backslash \\
1_{x y l}\end{array}$ & $\mathrm{OH}$ \\
\hline
\end{tabular}
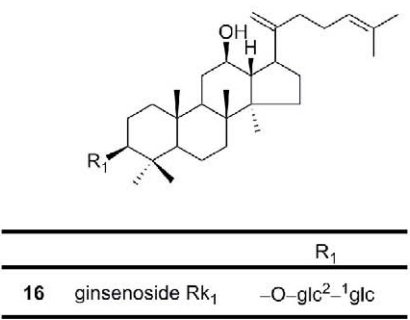

glc: $\beta$-D-glucopyranosyl

ara(p): $\alpha$-L-arabinopyranosyl

xyl: $\beta$-D-xylopyranosyl
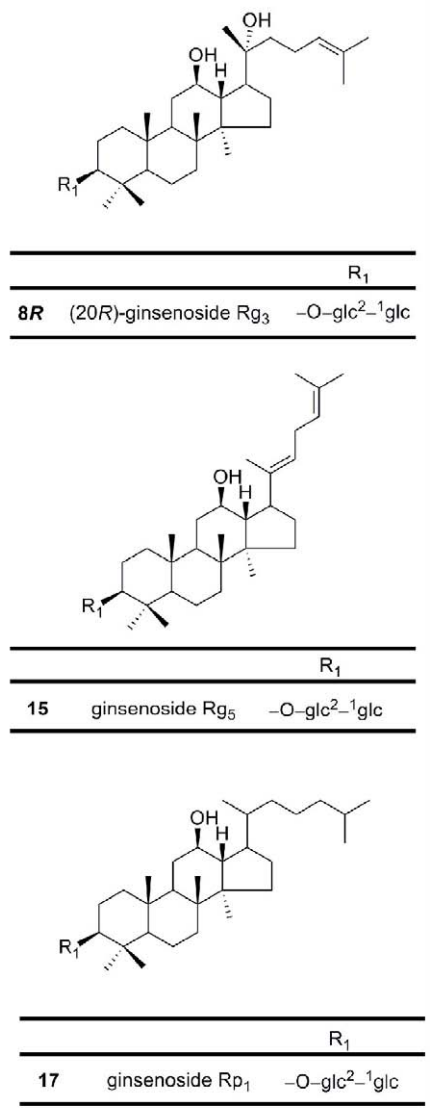

ara(f): $\alpha$-L-arabinofuranosyl

glcUA: $\beta$-D-glucuronic acid

FIGURE 1 | Chemical structures of protopanaxadiol-type ginsenosides.

referred to as "ginsan," with immunostimulatory activity (Kim et al., 1998; Shim et al., 2007).

\section{POLYYNES}

The polyynes are a group of organic compounds with alternating single and triple bonds. In ginseng, these include falcrinol (panaxynol), falcarintriol (panaxytriol), acetic acid, or linolenic acid (Lee and Zhao, 2009).

\section{FLAVONOIDS AND VOLATILE OILS}

Besides the compounds mentioned above, some flavonoids and volatile oils also have been isolated and identified from Panax genus (Lee and Zhao, 2009).

\section{STRUCTURE-ACTIVITY RELATIONSHIPS FOR GINSENOSIDE ANTICANCER ACTIVITY}

Ginseng saponins (except oleanic acid-type ginsenosides) possess a four trans-ring rigid steroid skeleton, with a modified side chain at $\mathrm{C}-20$ and sugar residues attached to the $-\mathrm{OH}$ of the aglycone. Structurally, most of the ginsenosides belong to PPD and PPT groups (Qi et al., 2010). For the PPD group, the sugar residues are attached to the $\beta-\mathrm{OH}$ at $\mathrm{C}-3$ and another $-\mathrm{OH}$ at $\mathrm{C}-20$ of the aglycone, e.g., ginsenosides Rb1, Rb2, Rc, Rd, Rg3, and Rh2. For the PPT group, sugar residues are attached to the $\alpha-\mathrm{OH}$ at C- 6 and another - $\mathrm{OH}$ at $\mathrm{C}-20$ of the aglycone sapogenin, e.g., ginsenosides Re, Rg1, Rh1, and notoginsenoside R1 (Christensen, 2009). Structure-activity relationships elucidate the association between chemical structures and the pharmacological activities for a series of compounds. As summarized in Table 1, the anticancer activities of ginseng saponins are related to the following factors, including the number of sugar molecules, number and position of hydroxyl groups, and stereoselectivity (Qi et al., 2010).

\section{NUMBER OF SUGAR MOLECULES}

Anticancer activities increase with the decrease in the number of sugar moieties in a ginsenoside molecule. Ginsenosides with four or more sugar molecules, such as Rbl and Rc, show no significant anti-proliferative effects (Yue et al., 2006; Li et al., 2009; Wang et al., 2009a); while Rd with three sugar residues weakly inhibits the growth of cancer cell (Yang et al., 2006; Li et al., 2009). 


\section{Protopanaxatriol-type}

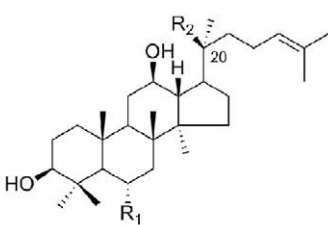

\begin{tabular}{|c|c|c|c|}
\hline & & $\mathrm{R}_{1}$ & $R_{2}$ \\
\hline 18 & ginsenoside $\mathrm{Re}$ & -O-glc ${ }^{2}-{ }^{1} \mathrm{rha}$ & $-\mathrm{O}-\mathrm{glc}$ \\
\hline 19 & ginsenoside Rf & $-\mathrm{O}-\mathrm{glc}^{2}-^{1} \mathrm{glc}$ & $\mathrm{OH}$ \\
\hline 20 & ginsenoside $\mathrm{Rg}_{1}$ & $-0-$ glc & $-\mathrm{O}-\mathrm{glc}$ \\
\hline 21 & (20S)-ginsenoside $\mathrm{Rg}_{2}$ & - $0-\mathrm{glc}^{2}-{ }^{1} \mathrm{rha}$ & $\mathrm{OH}$ \\
\hline 22 & ginsenoside $\mathrm{Rh}_{1}$ & $-\mathrm{O}-\mathrm{glc}$ & $\mathrm{OH}$ \\
\hline 23 & 20-glucoginsenoside Rf & O $\mathrm{glc}^{2}-1 \mathrm{glc}$ & $-\mathrm{O}-\mathrm{glc}$ \\
\hline 24 & notoginsenoside $R_{1}$ & $-0-g \mid c^{2}-{ }^{1} x y l$ & $-\mathrm{O}$ gle \\
\hline 25 & notoginsenoside $R_{2}$ & $-0-g^{2}{ }^{2}-{ }^{1} x y l$ & $\mathrm{OH}$ \\
\hline
\end{tabular}

Ocotillol-type

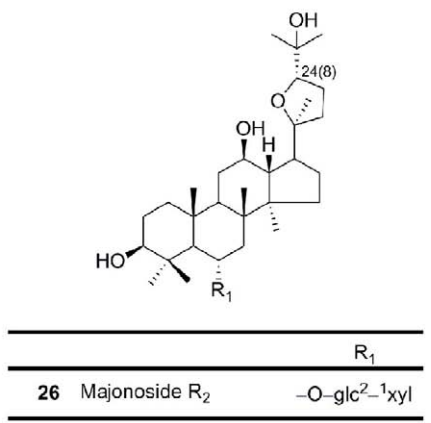

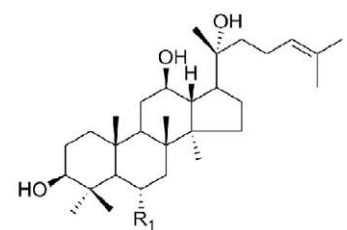

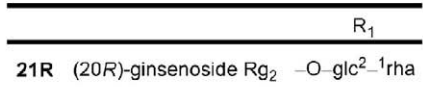

$21 \mathrm{R}(20 \mathrm{R})$-ginsenoside $\mathrm{Rg}_{2}-\mathrm{O} \mathrm{glc}^{2}-{ }^{1}$ rha

Oleanic Acid-type
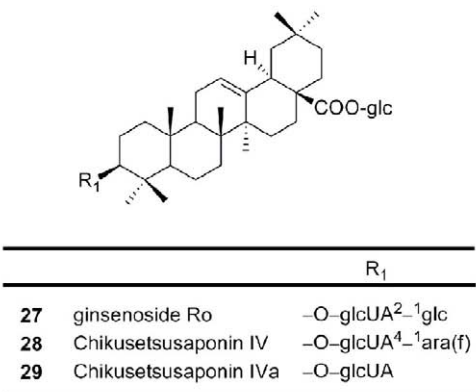

FIGURE 2 | Chemical structures of protopanaxatriol-type, ocotillol-type and oleanic acid-type ginsenosides.

Ginsenosides Rg3 (two sugar residues), Rh2 (one sugar residue), IH-901 (one sugar residue), PPT (no sugar residues), and PPD (no sugar residues) inhibit different types of cancer cells and also enhance the efficacy of conventional chemotherapy agents when given along with them (Hasegawa et al., 1995; Yue et al., 2006; Wang et al., 2007a; Yu et al., 2007). Rh2, 25-OH-PPD, and PPD show 5- to 15-fold relatively stronger anti-proliferative effects than Rg3 (Wang et al., 2007b). Among these compounds, PPD with no sugar residue shows the most potent anticancer activity. Qi et al. (2010) claim that introducing acetyl groups at selected positions increases the anticancer activity of PPD. It has also been suggested that neoglycorandomization might also increase anticancer properties (Langenhan et al., 2005). One might also expect to improve anticancer activity if heteroatoms like nitrogen and sulfur atoms are integrated into the steroid core structure or on the side chain.

Introduction of lipophilic groups in the side chains has been shown to increase anti-proliferative activity (Qi et al., 2010). For example, between the novel ginsenosides 25-OH-PPD and 25$\mathrm{OCH}_{3}-\mathrm{PPD}$, both isolated from the fruits of $P$. notoginseng, the latter shows a lower $\mathrm{IC}_{50}$ value in pancreatic cancer cell line (Wang et al., 2009b,c). This type of modification may also improve the pharmacokinetic properties of the compound (Wang et al., 2008b, 2009a,b). A related linear relationship has been observed between Log Ps (also referred to as the lipophilicity) and Log $\mathrm{IC}_{50}$ of ginsenosides (Li et al., 2009). The presence of sugar moieties reduces the hydrophobic character of the compounds and decreases the permeability of the cell membrane. As interaction with the cell membrane decreases, so do the anticancer effects. Thus we see that in general, anticancer activity is inversely correlated to the number of sugar residues; a fact that may be attributed to the cellular uptake capability of the ginsenosides. The cellular uptake ratios of ginsenosides on cancer cells probably decrease with the increase of sugar numbers, due to progressive decrease in hydrophobicity (Ha et al., 2010).

\section{SUGAR LINKAGE AT C-6}

Differences in sugar linkage positions may also influence biological responses. The C-6 substituent differentiates the PPD and PPT groups of ginsenosides structurally. Ginsenoside Rh2 (PPD type) and Rh1 (PPT type), which possess a glucose linkage at C-3 and C6 , respectively, have similar chemical structures, but the anticancer effect of Rh2 is stronger than that of Rh1. F1 (20-O-glc-PPT) and Rh1 (6-O-glc-PPT) have the same number of sugar moieties and the same molecular weight, with different glucose attachment positions at C-20 and C-6, respectively. In a study on prostate cancer cell lines, F1 showed significantly higher cell inhibition than Rh1 (Li et al., 2009). 
Table 1 | Possible structure-activity relationships of ginsenosides against cancer.

\begin{tabular}{|c|c|c|c|c|c|c|c|c|}
\hline \multirow[t]{2}{*}{ Ginsenoside } & \multirow[t]{2}{*}{ Nucleus } & \multirow{2}{*}{$\begin{array}{l}\text { No. of } \\
\text { sugars }\end{array}$} & \multicolumn{4}{|c|}{ Position of sugars/OH } & \multirow[t]{2}{*}{ Anticancer activity } & \multirow[t]{2}{*}{ Reference } \\
\hline & & & C-3 & C-6 & C-12 & C-20 & & \\
\hline Ra1 & PPD & 5 & 2 & 0 & $1-\mathrm{OH}$ & 3 & None reported & \\
\hline Ra2 & PPD & 5 & 2 & 0 & $1-\mathrm{OH}$ & 3 & None reported & \\
\hline Rb1 & PPD & 4 & 2 & 0 & $1-\mathrm{OH}$ & 2 & Weakly anti-proliferative; anti-angiogenic & Leung et al. (2007) \\
\hline $\mathrm{Rb} 2$ & PPD & 4 & 2 & 0 & $1-\mathrm{OH}$ & 2 & Weakly anti-proliferative; anti-angiogenic & $\begin{array}{l}\text { Mochizuki et al. (1995), Park and } \\
\text { Cho (2009) }\end{array}$ \\
\hline Rb3 & PPD & 4 & 2 & 0 & $1-\mathrm{OH}$ & 2 & No anti-anti-proliferative activity & Xie et al. (2009) \\
\hline $\mathrm{Rc}$ & PPD & 4 & 2 & 0 & $1-\mathrm{OH}$ & 2 & No anti-proliferative activity & Wang et al. (2009a), Li et al. (2009) \\
\hline $\mathrm{Rd}$ & PPD & 4 & 2 & 0 & $1-\mathrm{OH}$ & 2 & No significant anti-proliferative activity & Wang et al. (2009a), Li et al. (2009) \\
\hline Compound $\mathrm{K}$ & PPD & 1 & 1 & 0 & $1-\mathrm{OH}$ & 0 & Weakly inhibits cancer cell growth & Wang et al. (2007a) \\
\hline $\operatorname{Re}$ & PPT & 3 & $1-\mathrm{OH}$ & 2 & $1-\mathrm{OH}$ & 1 & Not reported & \\
\hline Rf & PPT & 1 & $1-\mathrm{OH}$ & 1 & $1-\mathrm{OH}$ & $1-\mathrm{OH}$ & Not reported & \\
\hline $\operatorname{Rg} 1$ & PPT & 2 & $1-\mathrm{OH}$ & 1 & $1-\mathrm{OH}$ & 1 & Anti-proliferative & Wang et al. (2007a) \\
\hline Rg2 & PPT & 3 & 1 & 2 & $1-\mathrm{OH}$ & $1-\mathrm{OH}$ & Anti-genotoxic & Wang et al. (2007a) \\
\hline Rg3 & PPD & 2 & 2 & 0 & $1-\mathrm{OH}$ & $1-\mathrm{OH}$ & Anti-proliferative, apoptotic & Wang et al. (2007a) \\
\hline Rh1 & PPT & 1 & $1-\mathrm{OH}$ & 1 & $1-\mathrm{OH}$ & $1-\mathrm{OH}$ & Strongly anti-proliferative & Jung et al. $(2010 a, b)$ \\
\hline Rh2 & PPD & 1 & 1 & 0 & $1-\mathrm{OH}$ & $1-\mathrm{OH}$ & Strongly apoptotic & Cheng et al. (2005) \\
\hline 25-OH-PРТ & PPT & 0 & $1-\mathrm{OH}$ & $1-\mathrm{OH}$ & $1-\mathrm{OH}$ & $1-\mathrm{OH}$ & Weakly anti-proliferative & $\begin{array}{l}\text { Wang et al. (2007b), Wang et al. } \\
\text { (2008a) }\end{array}$ \\
\hline 25-OH-PPD & PPD & 0 & $1-\mathrm{OH}$ & 0 & $1-\mathrm{OH}$ & $1-\mathrm{OH}$ & Apoptosis; anti-proliferation & $\begin{array}{l}\text { Wang et al. (2007b), Wang et al. } \\
\text { (2008a), Wang et al. (2009b) }\end{array}$ \\
\hline $25-\mathrm{OCH}_{3}-\mathrm{PPD}$ & PPD & 0 & $1-\mathrm{OH}$ & 0 & $1-\mathrm{OH}$ & $1-\mathrm{OH}$ & Highly anti-proliferative and anti-apoptotic & $\begin{array}{l}\text { Wang et al. (2008b), Wang et al. } \\
\text { (2009a), Wang et al. (2009b) }\end{array}$ \\
\hline
\end{tabular}

PPD, protopanaxadiol-type; PPT, protopanaxatriol-type.

With a sugar substitute at C-6, the anticancer activity of ginsenosides is decreased compared to activity with linkages at C-3 or C-20. Molecular modeling and docking experiments confirm that the presence of a sugar moiety at C-6 increases the steric hindrance for these molecules to bind to their target proteins by blocking entrance into the extracellular binding pocket, and thus significantly reducing the anticancer activities of ginsenosides (Chen et al., 2009).

\section{HYDROXYL GROUPS}

It is known that polar substances interact with phospholipid head groups in the hydrophilic domain of the cell membrane. Ginsenosides interact with the $\beta-\mathrm{OH}$ of the cholesterol in the cell membrane and intercalate themselves into the plasma membrane. This leads to changes in membrane fluidity, and thus affects membrane function, eliciting a cellular response. This ability to insert and orient with the membrane is influenced by the number and site of polar hydroxyl groups. Differences in the number and position of hydroxyl groups influence pharmacological activity. Elimination of the double bond at C-24/25 and addition of hydroxyl or methoxyl at C-25 increases the anticancer potential of ginsenosides. The anticancer activities of 25- $\mathrm{OCH}_{3}-\mathrm{PPD}, 25-\mathrm{OH}-\mathrm{PPD}, 25-\mathrm{OH}-\mathrm{PPT}, \mathrm{PPD}, \mathrm{Rh} 2$, and $\mathrm{Rg} 3$ have been systematically compared. $25-\mathrm{OCH}_{3}-\mathrm{PPD}$ and $25-\mathrm{OH}-$ PPD show the most potent anti-proliferative, pro-apoptotic, cell cycle regulatory and inhibitory effects of tumor growth in vivo and appear to be promising candidates for further development as novel anticancer agents (Wang et al., 2007b, 2008a,b, 2009a,b).

Dehydration at C-20 increases the bioactivity of ginsenosides (Kang et al., 2006). Rg5 differs from Rg3 only by the presence of a hydroxyl group at C-20 in Rg3 and is approximately four times more effective than $\mathrm{Rg} 3$ at inhibiting cell proliferation (Lee et al., 1997; Shin et al., 2006). Rh3, however, is a dehydration product at $\mathrm{C}-20$ of $\mathrm{Rh} 2$; both $\mathrm{Rh} 2$ and $\mathrm{Rh} 3$ induce differentiation of promyelocytic leukemia HL-60 cells, but the potency of Rh2 seems to be higher (Kim et al., 1998).

\section{STEREOSELECTIVITY OF 20(S) AND 20(R)}

$20(S)$ and $20(R)$ forms of ginsenosides are stereoisomers of each other that depend on the orientation of the $\mathrm{C}-20$ hydroxyl in ginsenosides. $20(S)-\mathrm{OH}$ is spatially close to the C-12 hydroxyl of ginsenosides while $20(R)-\mathrm{OH}$ is far. This difference in the stereochemistry produces different pharmacological effects. $20(S)$-Rg3 scavenges hydroxyl radicals better than $20(R)-\mathrm{Rg} 3$ (Lee et al, 2008). 20(S)-Rg3 is better aligned with the hydroxyl acceptor group in the ion channels than $20(R)-\mathrm{Rg} 3$, making $20(S)-\mathrm{Rg} 3$ an efficient regulator of voltage-dependent ion channels. Voltagesensitive ion channels have been shown to play a significant role in the progression of cancer (Jeong et al., 2004; Fiske et al., 2006). In general, the $20(S)$ compounds have been shown to possess better anti-proliferative effects than their $20(R)$ counterparts whereas 
$20(R)$ compounds such as $20(R)-\operatorname{Rg} 3$ have been shown to inhibit cancer cell invasion and metastasis.

Although a limited effect against cancer is observed, 20(R)Rh2 inhibits osteoclast formation better than $20(S)-\mathrm{Rh} 2$. It is possible that the anti-tumor properties of $20(R)$ ginsenosides are in part mediated through their angiosuppressive activity. These observations imply that the stereostructure of the C-20 hydroxyl may influence the biological and pharmacological effects of ginsenosides (Yue et al., 2006; Qi et al., 2010).

\section{METABOLISM}

When taken orally, PPD-type ginsenosides are mostly metabolized by anaerobic intestinal bacteria such as Bacteroides, Fusobacterium, Eubacterium, and Provetella to a PPD monoglucoside, compound $\mathrm{K}$, via a step-wise cleavage of the sugar moieties (Lee et al., 2009a). In humans, compound $\mathrm{K}$ may be detected in the plasma from $7 \mathrm{~h}$ after the intake of PPD-type ginsenosides and in urine from $12 \mathrm{~h}$ after the intake. These findings suggest that compound $\mathrm{K}$ is the final metabolite of PPD-type ginsenosides (Lee et al., 2009a). Also, compound K exhibits moderate inhibition of the CYP2C9 activity, while PPD and PPT exhibit potent competitive inhibition against CYP3A4 activity (Hasegawa et al., 1996; Tawab et al., 2003).

\section{MOLECULAR MECHANISMS OF ANTICANCER ACTIVITIES OF GINSENG AND GINSENG PRODUCTS}

The initiation of tumorigenesis involves DNA alteration, which may be heritable in progeny cells. These alterations include mutations, oncogene activation rearrangements, amplifications, and methylation. The commencement of this transformation process is irreversible and is modified by agents that may act as promoters. Initiation and promotion give rise to an abnormal expression of cellular genes whose interaction hormones with cellular receptors trigger a cascade of intracellular biochemical signals resulting in the activation and repression of various subsets of genes. Hence, determining the molecular mechanisms in the development and progression of the neoplastic process is essential for understanding the activity of any compound. Although anticancer activities of ginseng products have been widely reported, the exact mechanisms of action are not fully understood. Based on the existing reports, we summarize the possible molecular mechanisms by which ginsenosides exert anticancer effects in the following text (Table 2; Figure 3).

\section{MODULATION OF TUMOR CELL GROWTH, CELL CYCLE, AND CELL DEATH (FIGURES 4 AND 5) \\ Effects on DNA damage}

An aqueous extract of ginseng root has been shown to exert a radioprotective effect against $\gamma$-ray induced DNA double stranded breaks and repair in cultured mouse lymphocytes; and reduce the relative strand scission factor (RSSF) by a factor of 2 (Kim et al., 1996). Several studies have shown that ginseng root extracts exhibit both lipid-soluble and water-soluble antioxidant activity (Lee et al., 2005b). This antioxidant action is mediated through free radical scavenging and through upregulation of antioxidant enzymes, thus attenuating DNA degradation. Both $\mathrm{Cu} / \mathrm{Zn}$ superoxide dismutase $(\mathrm{Cu} / \mathrm{Zn}-\mathrm{SOD}$ or SOD1) and catalase (CAT) are key enzymes involved in the metabolism of oxygen free radicals, and ginsenosides have been associated with the upregulation of these two enzymes at the level of gene expression and transcription (Rhee et al., 1991; Zhang et al., 1996; Kitts et al., 2000; Kim et al., 2002; Keum et al., 2003).

\section{Effect on proliferation and differentiation}

Studies show that, of all naturally occurring ginsenosides in the American ginseng plant $\mathrm{Rg} 3$, has the most potent effect on inhibition of cell proliferation. In fact, steam treatment increasing the concentration of ginsenoside $\mathrm{Rg} 3$ augments the anti-proliferative activities of American ginseng (Wang et al., 2007a). In the human prostate carcinoma LNCaP cell line, ginsenoside Rg3 displays good growth inhibitory activity. The expression of biomarker genes, including prostate specific antigen (PSA), androgen receptor (AR) and 5alpha-reductase (5alphaR), and that of the proliferating cell nuclear antigen (PCNA) are suppressed (Liu et al., 2000). Rh2 obtained from Asian ginseng also shows anti-proliferation, differentiation, and chemopreventive effects in various cancer cell types (Oh et al., 1999).

Studies show that p21 is an important target in mediating the anti-proliferative activities of ginseng. American ginseng extract (AGE) inhibits breast cancer cell proliferation by induction of this important cyclin inhibitor protein (King and Murphy, 2006). Rh2 has also been shown to inhibit cell growth in a concentrationdependent reversible manner, inducing a G1 arrest in cell cycle progression by upregulating the expression of p21 (Oh et al., 1999).

Ginseng is found to have the ability to induce transformation of neoplastic cells into normal cells (Lee et al., 2009b). Rh2 present in red ginseng inhibits the growth and colony forming ability of Morris hepatoma cells in soft agar suspension culture, and stimulates serum protein synthesis of these cells, thus transforming the neoplastic cells functionally and morphologically to those resembling original normal liver cells, a process known as "redifferentiation" (Odashima et al., 1989). Red ginseng (also known as Korean red ginseng) is a processed form of unpeeled ginseng that has been heated, either through steaming or sun-drying and contains predominantly the PPD ginsenosides (Lui and Staba, 1980).

Similarly, Rh1 and Rh2 cause differentiation of F9 teratocarcinoma stem cells via binding to a steroid receptor (Lee et al., 1993). Furthermore, Rh2 significantly induces B16 cell differentiation and increases melanin synthesis in B16 cells (Xia and Han, 1996). Cytotoxic effects of the PPD or PPT type of ginsenosides are inversely proportional both to the number of sugars attached to the aglycones and to the number of hydroxyl groups of the aglycones. Surprisingly, the type of side chain and the configuration of the hydroxyl group at C-3 in aglycones have not been found to play a significant role in determining cytotoxicity (Atopkina et al., 1999). Rg3 and Rh2 inhibit the proliferation of prostate cancer cell lines LNCaP and PC3, which may be associated with modulation of MAP kinases (MAPK; Kim et al., 2004). In addition, 20(S)-PPD and $\mathrm{Rh} 2$ reduce cell proliferation and increase sub-G1 cells in two cultured intestinal cell lines, Int-407 and Caco-2 (Popovich and Kitts, 2004).

\section{Cell cycle regulation and regulation of p53/p21/MDM2 pathway}

The cell cycle is a set of events, resulting in cell growth and division into two daughter cells. The stages are G1-S-G2-M. The G1-S transition in the cell cycle is controlled primarily via cyclin 
Table 2 | Summary of the anticancer activities of major ginsenoside.

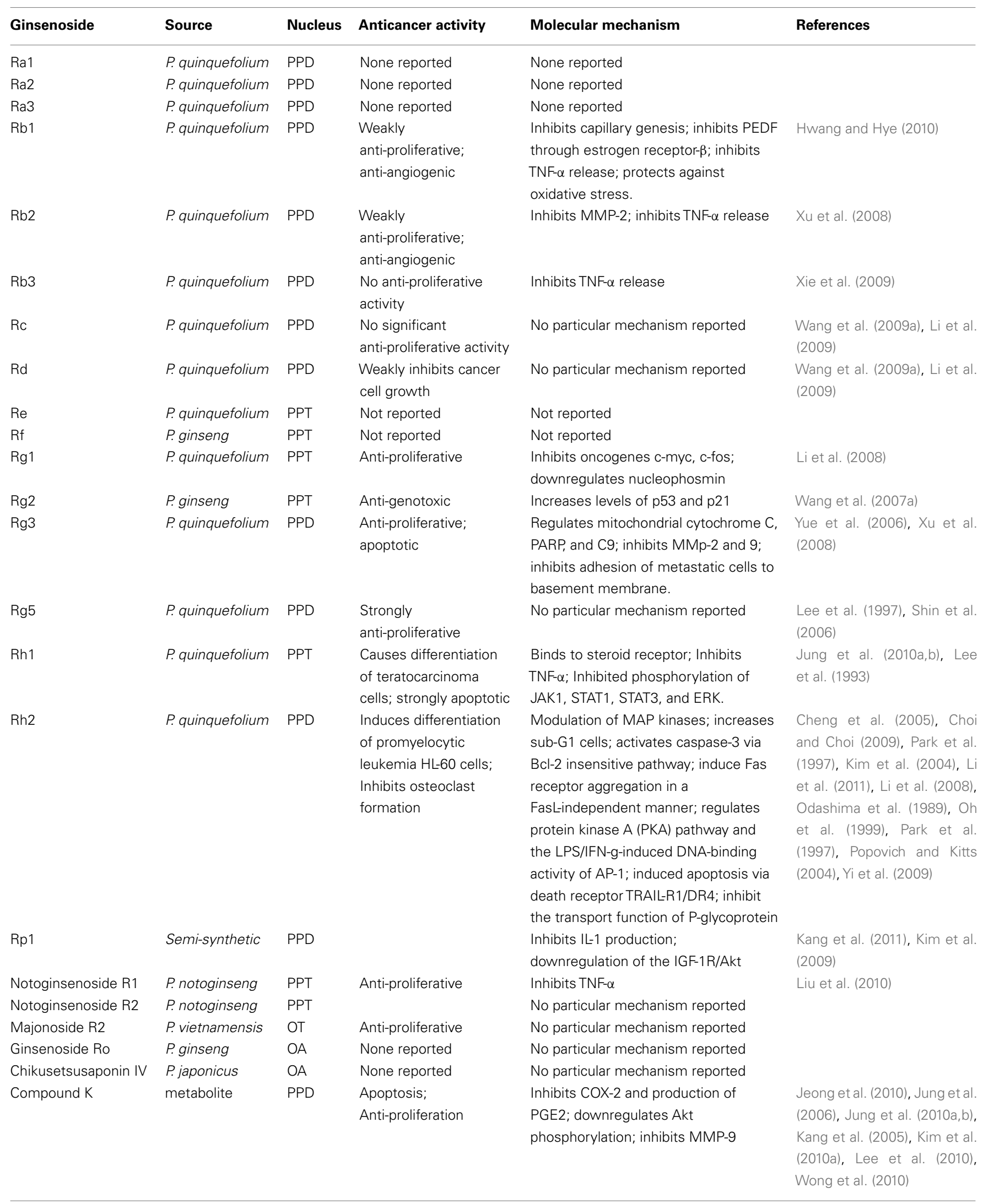


Table 2 | Continued

\begin{tabular}{|c|c|c|c|c|c|}
\hline Ginsenoside & Source & Nucleus & Anticancer activity & Molecular mechanism & References \\
\hline 25-OH-РPТ & P. notoginseng & PPT & Weakly anti-proliferative & No particular mechanism reported & $\begin{array}{l}\text { Wang et al. (2007b), Wang } \\
\text { et al. (2008a) }\end{array}$ \\
\hline 25-OH-PPD & P. notoginseng & PPD & $\begin{array}{l}\text { Apoptosis; } \\
\text { anti-proliferation }\end{array}$ & $\begin{array}{l}\text { Downregulation of MDM2; activation } \\
\text { of caspases; increase in } \mathrm{p} 21\end{array}$ & $\begin{array}{l}\text { Wang et al. (2007b), Wang } \\
\text { et al. (2008a), Wang et al. } \\
\text { (2009b) }\end{array}$ \\
\hline $25-\mathrm{OCH}_{3}-\mathrm{PPD}$ & P. notoginseng & PPD & $\begin{array}{l}\text { Apoptosis; } \\
\text { anti-proliferation }\end{array}$ & $\begin{array}{l}\text { Downregulation of MDM2, activation } \\
\text { of caspases, increase in } \mathrm{p} 21\end{array}$ & $\begin{array}{l}\text { Wang et al. (2008b), Wang } \\
\text { et al. (2009a), Wang et al. } \\
\text { (2009b) }\end{array}$ \\
\hline
\end{tabular}

PPD, protopanaxadiol-type; PPT, protopanaxatriol-type; OT, ocotillo-type; OA, oleanic acid-type.

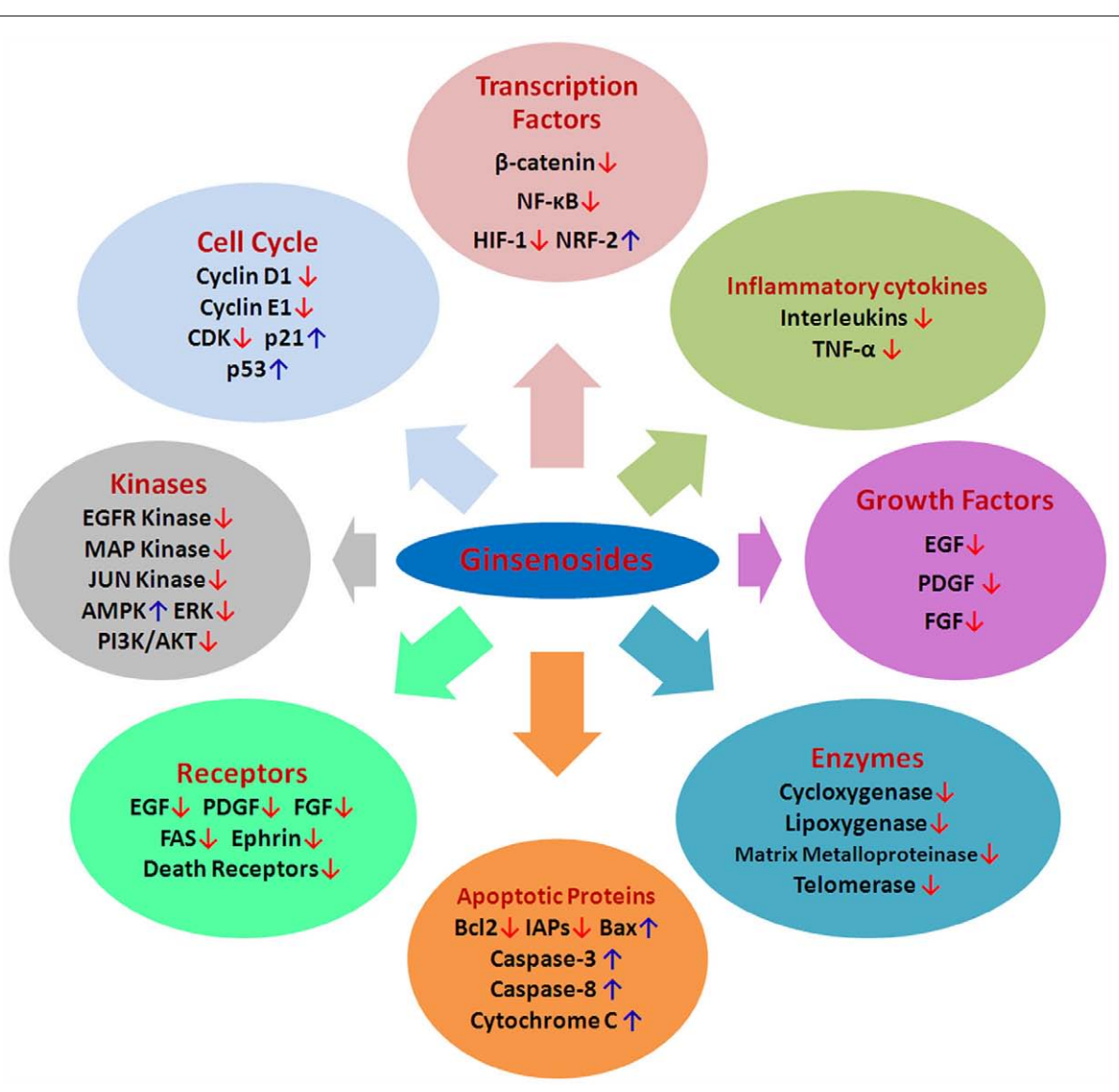

FIGURE 3 | Possible cellular and molecular mechanisms of ginsenosides aginst cancer. CDKs, cyclin-dependent kinases; MDM2, murine double minute-2; VEGF, vascular endothelial growth factor; bFGF, basic fibroblast growth factor; PDGF, platelet derived growth factor, MMP, matrix metalloproteinase; IAP, inhibitory apoptotic protein; TNF, tumor necrosis factor; NF-kB, nuclear factor $\kappa B$; PI3K, Phosphatidylinositol 3-kinase; HIF-1, hypoxia-inducible factor-1; ERK, extracellular signal-regulated kinase; NRF2, nuclear factor (erythroid-derived 2)-like; AMPK, 5' AMP-activated protein kinase; EGF, epithelial growth factor; $\uparrow$, upregulation; $\downarrow$, downregulation. pathways, including cyclin D1 and cyclin cdks 2, 4, and 6. These proteins are, in turn, regulated by $\mathrm{p} 21$ and p 27 . At the very center of this cell cycle regulation is the tumor suppressor and transcription factor p53. The tumor suppressor p53 plays an important role in regulation of cell cycle and apoptosis. The MDM2 oncoprotein is an E3 ubiquitin ligase negatively regulates p 53 function by conjugating ubiquitin to p53; thus altering its cellular localization and tagging it for proteasomal degradation.

Panaxydol, a polyacetylene compound obtained from $P$ ginseng, induces cell cycle arrest at the G1 to $S$ transition in HepG2 hepatoma cancer cells with concomitant increase in the protein levels of $\mathrm{p} 21, \mathrm{pRb}$, and hypophosphorylated $\mathrm{pRb}$ in a 


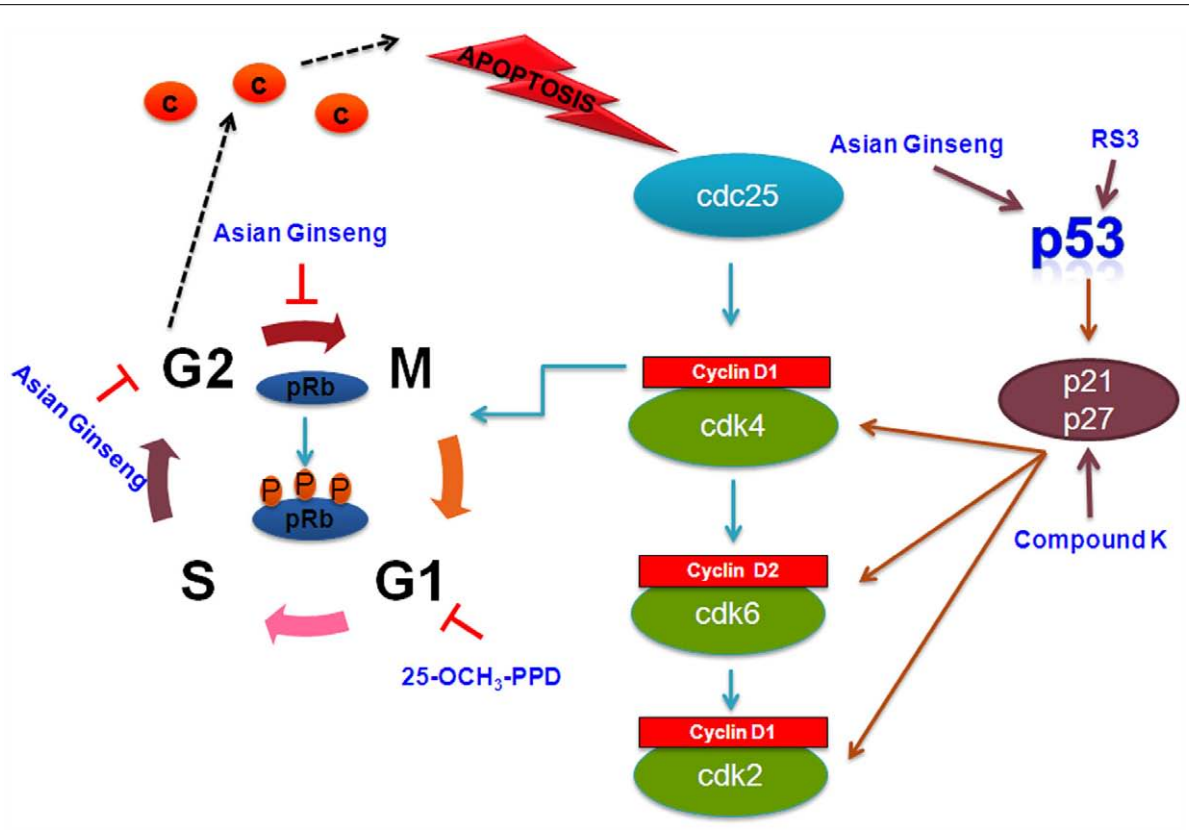

FIGURE 4 | Cell signaling pathways involved in cell cycle arrest targeted by selected ginsenosides. Rb, retinoblastoma protein.

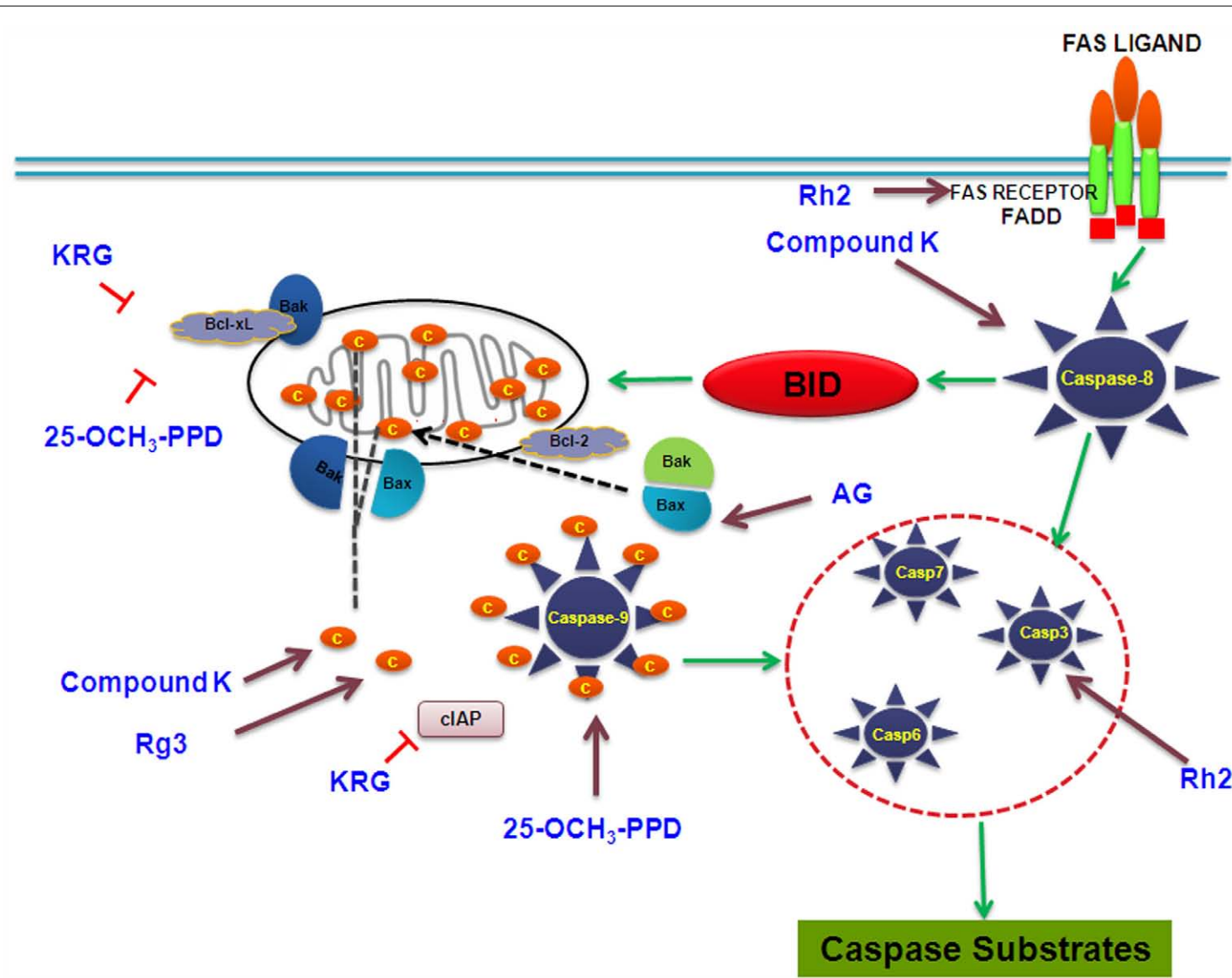

FIGURE 5 | Cell signaling pathways involved in apoptotic response targeted by selected ginsenosides. KRG, Korean red ginseng; AG: American ginseng 
dose-dependent manner (Guo et al., 2009). Rs3, a panaxadiol type ginsenoside isolated from the Korean red ginseng, upregulates p53 leading to induction of p21 which in turn initiates growth arrest and apoptosis. Studies show that ginsenosides selectively increase p53 expression at G2 phase of carcinoma cells and release cytochrome $c$ from mitochondria, which is an essential requirement for apoptosis. An aqueous extract of Asian ginseng has been shown to induce MAPK and p53 signaling in LLC-1 cells, which suppresses cyclin B-cdc2 complex and in turn induces G2-M arrest and apoptosis. Compound $\mathrm{K}$ is known to induce the expression of p21, independently of p53 in U937 human monocytic leukemia cells (Kang et al., 2005; Jung et al., 2006; Wong et al., 2010). Wang et al. demonstrate that 25-OH-PPD inhibits cell growth and proliferation, induces apoptosis, and leads to arrest in the G1 phase of the cell cycle in prostate cancer. Further, in both PC3 and LNCaP prostate cancer cell lines, 25-OH-PPD reduces expression of MDM2, E2F1, Bcl-2, cdk2/4/6, and cyclin D1, which correlates with cell cycle arrest in G1 phase and anti-proliferative activity (Wang et al., 2007b).

\section{Induction of cell death}

There are two major pathways of cell death: apoptosis (death by suicide) and necrosis (death by injury). Apoptosis, also known as programmed cell death, involves a series of biochemical events, leading to characteristic cell morphology and death. It is typically accompanied by activation of specific proteases known as caspases (Nicholson and Thornberry, 1997). Necrosis is caused by external factors, such as infection, toxins, or trauma. Additional cell death mechanisms, such as autophagy (degradation of a cell's own components through the lysosomal action), entosis (internalization of a cell detached from the basement membrane into another cell; Overholtzer et al., 2007), paraptosis (non-apoptotic cell death mediated by MAPKs; Sperandio et al., 2004), and anoikis have been defined more recently.

Caspase activation. Caspases, or cysteine-aspartic acid proteases, are a family of cysteine proteases that play essential roles in apoptosis, necrosis, and inflammation. Numerous reports suggest the involvement of caspases in ginsenoside-induced apoptosis. Ginsenosides cause DNA damage, endoplasmic reticulum (ER) stress, and mitochondrial-dependent-induced apoptosis through the activation of caspase-3 (Cheng et al., 2005). Compound K has been shown to cause loss of the mitochondrial membrane potential followed by cytochrome $\mathrm{c}$ release from the mitochondria, resulting in the activation of caspase- $9,-3$, and concomitant poly ADP-ribosyl polymerase (PARP) cleavage, which are the indicators of caspase-dependent apoptosis (Lee et al., 2010). Caspase-8 plays a key role in compound K-stimulated apoptosis via the activation of caspase-3 directly or indirectly through Bid cleavage, cytochrome $c$ release, and caspase- 9 activation. $\operatorname{Rg} 3$ has been shown to facilitate the release of mitochondrial cytochrome $c$, PARP, caspase-9, and caspase-3 (Lee et al., 2010).

Aqueous extracts of American ginseng activate BAX and increase the levels of cleaved caspase-3 in p21-deficient cells causing cell death (King and Murphy, 2010). Korean red ginseng causes an increase in apoptosis, by downregulation of anti-apoptotic $\mathrm{Bcl}-2, \mathrm{Bcl}-\mathrm{XL}$, and IAPs family members, and the activation of caspase-3 (Cheng et al., 2005). Rh2 activates caspase-3 via Bcl-2 insensitive pathway in the human hepatoma cell line SK-HEP1 (Park et al., 2010a). In structure and apoptosis relationship, the presence of sugars in PPD and PPT aglycone structures has been found to reduce the potency to induce apoptosis in the human leukemia (THP-1) cell line (Popovich and Kitts, 2002).

Induction of death receptors. Death receptors are cell surface receptors that transmit apoptotic signals initiated by specific ligands such as Fas ligand, tumor necrosis factor- $\alpha$ (TNF- $\alpha$ ), and TRAIL (TNF related apoptosis-inducing ligand). These receptors play a crucial role in apoptosis and can activate a caspases- 8 dependent cascade within seconds of ligand binding. Induction of apoptosis via this mechanism is therefore very rapid. Studies show that the ginsenosides such as $\mathrm{Rh} 2$ induce apoptosis via death receptor TRAIL-R1/DR4 in the human lung adenocarcinoma cell line A549. However, expression of Bcl-2 protein in A549 cells does not block Rh2 mediated apoptosis, suggesting that the DR4 pathway acts independently of the Bcl-2 family (Cheng et al., 2005; Choi and Choi, 2009). Intestinal bacterial metabolites of ginseng saponin such as compound $\mathrm{K}$ induce apoptosis in human hepatoblastoma cells by late activation of caspase- 8 by Bid and DR5 (Lee et al., 2010). Contrastingly, studies with Korean RGE in U937 leukemia cell line show no change in levels of DR4, DR5, and TRAIL but the extract induces concomitant degradation of poly (ADP-ribose) polymerase, $\beta$-catenin and PLC- $\gamma 1$ substrate proteins of caspase-3 (Park et al., 2009).

FAS receptor aggregation. Fas receptor is the ligand for Fasactivated apoptosis. Binding of the ligand promotes receptor clustering, DISC formation, and the activation of the caspase cascade. The ginsenoside Rh2 is shown to induce Fas receptor aggregation in a FasL-independent manner (Yi et al., 2009). Apoptosis in the HeLa cell line NCE induced by Rh2 upregulates the Fas receptor protein in a dose-dependent manner (Park et al., 1997). Ginsenosides are able to inhibit the proliferation of cancer cells and induce apoptosis by downregulating the expression of c-myc and Bcl-2 and upregulating the expression of Fas and p53. They also induce the cell cycle arrest and apoptosis in gastric/colon cancer cells and stimulate the activity of caspase-8, initiating Fas signaling pathway of apoptosis (Yi et al., 2009).

Autophagy. Autophagy is a type of programmed cell death occurring in response to cellular stress and starvation. Unlike apoptosis, in autophagy there is no cell enlargement, bleb formation, vacuole development, and enlarged/swollen nuclei (Elliott and Reiners, 2008). The ginsenoside Rk1 obtained from heat processed ginseng induces both G1 phase arrest and autophagy, but not apoptosis, at an earlier stage of treatment. Rk1-induced autophagy is documented by the conversion of microtubule associated protein light chain 3 (LC3)-I to LC3-II, an autophagosome marker, and monodansylcadaverine (MDC) incorporation into autolysosomes (Ko et al., 2009).

\section{MODULATION OF PATHWAYS INVOLVING GROWTH SIGNALS}

Growth factors play a critical role in the proliferation of tumor cells. Molecules like EGF, HER2, FGF, vascular endothelial growth 
factor (VEGF), PDGF, and insulin growth factor (IGF)-1 have been associated with cell proliferation. The suppression of these growth factors or their receptors results in inhibition of tumor growth. For example, the inhibition of EGFR expression and decreased ERK1/2 activity attenuates cell survival and enhances induction of apoptosis in lung and pancreatic adenocarcinoma cells.

\section{Inhibition of growth factors and their receptors}

Several studies have shown that ginsenoside are capable of blocking VEGF. Rg3 is reported to downregulate the expressions of KDR (VEGF receptor-2) and VEGF protein and their mRNA in human lung squamous cancer SK-MES-1 cells (Wang et al., 2009d). It is reported that ginsenoside $\mathrm{Rg}_{3}$ and cyclophosphamide (CTX) exhibit a synergistic effect on the inhibition of growth and angiogenesis in mice transplanted with ovarian cancer cells (SKOV-3; Xu et al., 2007). The treated mice show decreased PCNA labeling index and the VEGF expression is also significantly lower. Ginsenosides have also been shown to completely block EGF-induced DNA synthesis and cell growth in primary cultured rabbit renal proximal tubular cells (PTCs; Han et al., 2002). In contrast, the PPT and PPD fractions only cause partial blockade. In addition, the EGF-induced increase of c-fos and c-jun gene expression is completely blocked by total ginsenosides and partially by PPT and PPD saponins (Han et al., 2002). Compound K reduces the secretion of VEGF and increases the secretion of pigment epithelium-derived factor (PEDF) in HUVECs. In addition, Compound K effectively disrupts bFGF-induced neovascularization in the Matrigel plugs excised from mice in vivo (Jeong et al., 2010). A recent study (Dougherty et al., 2011) suggests that compound $\mathrm{K}$ inhibits the activation of EGFR signals, including pEGFR, pErbB2, pERK, and $\mathrm{pAKT}$ in an inflammation associated colon cancer model based on a high fat western diet.

\section{Ephrin pathway}

Ephrin receptors belong to the tyrosine kinase family of transmembrane proteins, capable of influencing cell-cell interaction and cell migration. When Ephrins bind to Eph receptors, the bidirectional signaling of the Eph/ephrin axis is activated; this results in tumorigenesis and is associated with angiogenesis and metastasis in many types of human cancer. Previously, the inhibition of Eph/ephrin signaling as a novel strategy for cancer treatment has been investigated. Using ChIP and microarray techniques, Luo et al. show that ginsenosides $\mathrm{Rg} 3$ and $\mathrm{S}_{2} \mathrm{H}$ may exert effective anticancer activity through the Ephrin receptor pathway in human colorectal cancer cell line HCT116. The microarray analysis suggests that the activity of $\mathrm{Rg} 3$ is linked to upregulation of AKAPA $8 \mathrm{~L}$ (anchor protein) and downregulation of PITPNA (phosphatidylinositol transfer protein $\alpha$ ) genes (Park et al., 2005; Luo et al., 2008).

\section{INHIBITION OF ANGIOGENESIS}

Angiogenesis is the process by which new blood vessels are formed from pre-existing structures. It is a crucial step in tumor growth and metastasis by supplying oxygen and nutrients. Ginseng derivatives have been shown to inhibit tumor growth by influencing neovascularization and the angiogenesis-related properties of endothelial cells (ECs; Leung et al., 2007). Ginsenoside Rb1 has been shown to inhibit capillary morphogenesis of ECs by regulating expression of PEDF through the estrogen receptor $\alpha$ (Leung et al., 2007). 20(R)-Rg3 inhibits proliferation, formation of capillary tube, and chemoinvasion of ECs induced by VEGF (Yue et al., 2006). 20(R)-Rg3 also reduces microvascular sprouting in vitro and inhibits neovascularization induced by basic fibroblast growth factor in vivo (Yue et al., 2006). The angiosuppressive effect of $20(R)-\operatorname{Rg} 3$ may be related to the differential regulation of matrix metalloproteinases (MMP-2 and MMP-9) activities (Yue et al., 2006).

\section{ANTI-METASTATIC EFFECTS}

Metastases are multiple, widespread tumor colonies established by malignant cells that detach themselves from the original tumor and travel through the body often to distant sites. Some of these invading cells penetrate into a body cavity or the blood, lymph or spinal fluid and then are released forming tumors locally at the site of penetration. Enzymes capable of proteolytic degradation of extracellular matrix and basement membranes have been implicated in tumor progression and metastasis, especially the protease matrix metalloproteinase 9 (MMP-9). Matrix metalloproteinases, a family of zinc-dependent proteases, participate in several steps in tumor progression, including invasion, metastasis, and angiogenesis. Many studies implicate that the aberrant expression of MMP-9 plays an important role in tumor metastasis (Deryugina and Quigley, 2006).

$20(R)$ - and $20(S)-\operatorname{Rg} 3$ possess an ability to inhibit the lung metastasis of tumor cells such as B16-BL-6 melanoma and colon $26 \mathrm{M} 3.1$ by inhibition of the adhesion and invasion of tumor cells, and also by anti-angiogenesis activity (Mochizuki et al., 1995). Glucocorticoid receptor-induced downregulation of MMP-9 by panaxadiol (PD) and panaxatriol (PT) appear to be associated with the reduced invasive capacity of HT1080, a highly metastatic human fibrosarcoma cell line (Park et al., 1999).

Mochizuki et al. report that multiple administration of ginsenoside Rb2 after the intravenous inoculation of B16-BL6 melanoma cells results in a significant inhibition of tumor associated angiogenesis leading to suppression of lung metastases. In addition, the authors also show that Rg3 significantly inhibits the adhesion and invasion of B16-BL6 cells into reconstituted basement membranes (Matrigel; Mochizuki et al., 1995). Ginsenoside $\mathrm{Rb} 2$ has been reported to inhibit invasion to the basement membrane via MMP-2 suppression in some endometrial cancers such as HHUA and HEC-1-A cells, and can potentially be used as a medication for inhibition of secondary spreading of uterine endometrial cancers (Fujimoto et al., 2001). It is shown that ginsenoside $\mathrm{Rg} 3$ inhibits experimental pulmonary metastasis by highly metastatic mouse melanoma B16FE7 cells, by inhibition of the 1-oleoyl-lysophosphatidic acid (LPA)-triggered rise of intracellular $\mathrm{Ca}^{2+}$ (Shinkai et al., 1996). In addition, the invasive ability and MMP-9 expression of SKOV-3 cells decreases significantly after treatment with ginsenoside Rg3 (Xu et al., 2008). Compound $\mathrm{K}$ is effective in suppressing the expression of MMP-9 and thus inhibiting migration and invasion in metastatic murine colon adenocarcinoma cells (Choo et al., 2008). In another study, the aforementioned ginsenoside has also been shown to inhibit the secretion and protein expression of MMP-9 in astroglioma cells. The inhibitory effect of compound K on MMP-9 expression correlates with decreased MMP-9 mRNA levels and suppression 
of MMP-9 promoter activity. The compound K-mediated inhibition of MMP-9 gene expression occurs via activator protein-1 (AP-1) because its DNA-binding and transcriptional activities are suppressed by the drug (Jung et al., 2006).

Recently, a study (Yoon et al., 2012) has shown that treatment with the Rd inhibits migration and invasion of the liver cancer cell line HepG2. This is accomplished by reducing the expression of MMP-1, MMP-2, and MMP-7, by blocking MAPK signaling, by inhibition of AP-1 activation, and by inducing focal adhesion formation and decreasing vinculin localization and expression. This leads to a significant anti-metastatic effect. Earlier studies have reported that Rd has negligible anti-proliferative activities (Wang et al., 2007a).

\section{MODULATION OF KINASES (FIGURE 6) Inhibition of PI3K-Akt activation}

Akt (protein kinase B), a serine/threonine kinase, is a critical enzyme in signal transduction pathways involved in cell proliferation, apoptosis, and angiogenesis. Studies show that several ginsenosides such as compound $\mathrm{K}$ and PPDs inhibit the phosphorylation of Akt, mTOR, and their downstream substrates in a concentration- and time-dependent manner in human umbilical vein cells, and this inhibitory effect is seen downstream of phosphatidylinositol 3-kinase (PI3K). In fibroblast growth factor treated HUVEC cells, compound K downregulates the phosphorylation of Akt (Jeong et al., 2010). Additionally, in MCF-7 cells, 20(S)-PPD has been shown to synergistically enhance the cytotoxicity of tamoxifen by downregulating Akt, independently of estrogen receptor (Yu et al., 2007).

\section{Activation of c-jun kinase}

Studies show that activation of the JNK/c-Jun/AP-1 signal pathway induces the $\mathrm{p} 21$ activation, resulting in growth arrest. Compound $\mathrm{K}$ causes G1 phase arrest via the induction of $\mathrm{p} 21$ and activation of the JNK/AP-1 pathway. The apoptotic effect of compound $\mathrm{K}$ is exerted via the activation of c-Jun NH2-terminal kinase (JNK) and p38 MAPK (Kang et al., 2005; Jeong et al., 2010). Another study shows that panaxydol induces apoptosis through an increase in intracellular $\mathrm{Ca}^{2+}$ concentration, activation of JNK and p38 MAPK, and generation of reactive oxygen species (ROS) initially by NADPH oxidase and then by mitochondria. Apoptosis seen is caspase-dependent and occurs through a mitochondrial pathway utilizing generated ROS (Kim et al., 2011).

\section{Modulation of AMPK pathways}

AMP-activated protein kinase (AMPK) is a sensor of cellular energy states and is involved in apoptosis of cancer cells. Many cancers are characterized by increased expression and/or activity of enzymes (e.g., FAS and mTOR) that are inhibited by AMPK. Compound $\mathrm{K}$ is shown to exert cytotoxicity in MCF-7 human breast cancer cells through modulation of AMPK, followed by a decrease in cyclooxygenase-2 (COX-2) expression (Kim et al., 2010a). Compound $\mathrm{K}$ inhibits cell growth, induces apoptosis via generation of ROS, as well as decreasing COX-2 expression and prostaglandin E2 (PGE2) levels. These effects of compound $\mathrm{K}$ are induced via an AMPK-dependent pathway and are nullified by a specific AMPK inhibitor (Kim et al., 2010a).

\section{ANTI-INFLAMMATORY PATHWAYS}

Chronic inflammation is associated with increased cancer risk. The microenvironment provided by inflammatory cells is a crucial contributor in the neoplastic process, fostering proliferation, survival, and migration (Aggarwal and Shishodia, 2006). The inflammatory cells and regulators may facilitate angiogenesis and promote the growth, invasion, and metastasis of tumor cells.

Compound $\mathrm{K}$ suppresses the TNF- $\alpha$-induced activation of nuclear factor kappa-B (NF- $\mathrm{B}$ ), expression of MMP-9, migration and invasion of cancerous cells, thus indicating that ginsenosides have the potential to suppress inflammation related metastasis (Choo et al., 2008). American ginseng has been shown to inhibit induced COX-2 and NF- $\kappa$ B activation in MDA-MB-231 and MCF7 cell line (Peralta et al., 2009). Rg3 suppresses activation of NF- $\mathrm{B}$ inhibiting cancer cell growth in colon cancer cell lines SW620 and HCT116 in a dose-dependent manner (Kim et al., 2010b). Blockage of ROS by NAC/catalase inhibits activation of NF- $\kappa \mathrm{B}$ signaling increasing Rh2 induced cell death (Li et al., 2011).

The ginsenoside G-Rp1 dose-dependently inhibits interleukin1 (IL-1) production (at both mRNA and protein levels) from LPS-treated RAW264.7 cells without altering cell viability. This compound also downregulates I $\mathrm{B} \alpha$ phosphorylation and NF- $\mathrm{B}$ activation, but does not affect the upstream signaling enzymes such as MAPK and p85, a regulatory subunit of PI3K (Kim et al., 2009). PPD-type ginsenosides (G-Rb1 and G-Rb2) exhibit significant inhibition of TNF- $\alpha$ release with $\mathrm{IC}_{50}$ values of 48.0 and $27.9 \mathrm{mM}$, respectively (Park and Cho, 2009). Strong apoptosisinducing saponins, Rh1 and Rh2, the main intestinal metabolites of $\mathrm{Rg} 3$ have been shown to be inhibitors of proinflammatory TNF$\alpha$ and IL- $1 \mathrm{~b}$ in LPS/IFN-g-activated BV-2 cells, while increasing the expression of the anti-inflammatory cytokine IL-10 (Jung et al., 2010a,b). The prime targets of G-Rh2 are both the protein kinase A (PKA) pathway and the LPS/IFN-g-induced DNA-binding activity of AP-1, but not the CAMP responsive element binding protein or NF- $\mathrm{B}$. Both PPD and PPT type ginsenosides inhibit LPS-induced TNF $\alpha$ by blocking the phosphorylation of ERK 1/2, JNK, and cJun, as well as blocking NF- $\mathrm{B}$ activation (Wu et al., 2007). RGE from steamed and dried P. ginseng is seen to inhibit Helicobacter pylori-induced MAPK signaling by repressing either nuclear factor NF-кB-DNA-binding activity or release of IL-8 and COX-2 in gastric epithelial cells (Park et al., 2007). RGE also inactivates c-Jun phosphorylation and represses redox-sensitive transcriptional activation, leading to reduced expression of IL-8 and 5-LOX mRNA in gastric mucosal cells (Park et al., 2007).

Rh1 significantly suppresses IFN- $\gamma$-induced iNOS promoter activity by inhibiting DNA-binding of several transcription factors, such as NF- $\kappa$ B, IRF-1, and STAT1 (Jung et al., 2010a). Furthermore, Rh1 inhibits the phosphorylation of JAK1, STAT1, STAT3, and ERK, which are upstream signaling molecules for IFN- $\gamma$ induced iNOS gene expression. This study also demonstrates that Rh1 inhibits IFN- $\gamma$-induced JAK/STAT and ERK signaling pathways and downstream transcription factors, and thereby iNOS gene expression.

Tumor promotion often accompanies an elevated ornithine decarboxylase (ODC) activity, acute inflammation and induction of COX-2 activity. Compound $\mathrm{K}$, when applied topically onto shaven backs of female ICR mice leads to the inhibition of the 


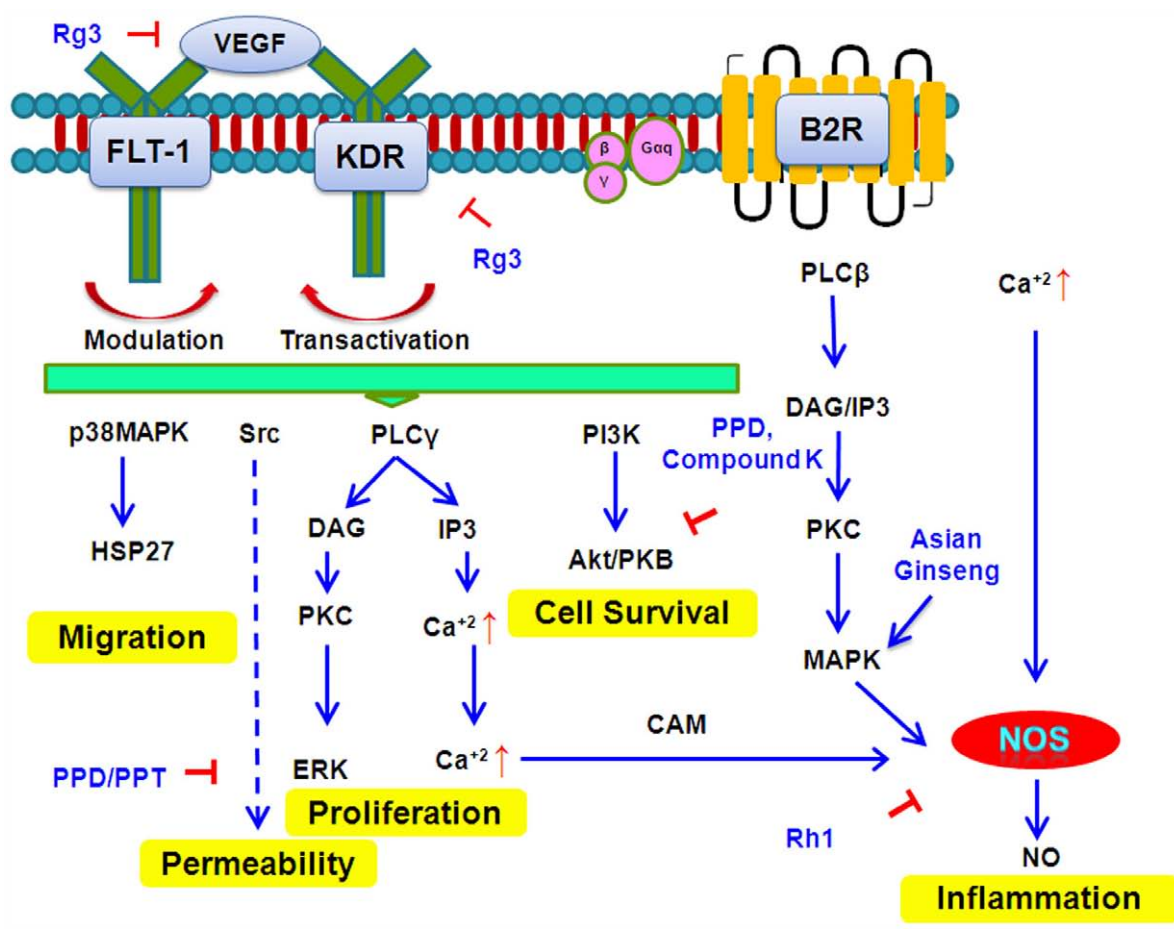

FIGURE 6 | Signal Transduction pathways targeted by selected ginsenosides.

12-O-tetradecanoylphorbol-13-acetate (TPA) induced expression of COX-2 and production of prostaglandin E2 (Lee et al., 2005a). The eukaryotic transcription factor NF- $\mathrm{B}$ has been involved in intracellular signaling pathways associated with inflammation and carcinogenesis. Compound $\mathrm{K}$ has been seen to inhibit the activation of ERK1/2 and Akt signaling. When compound $\mathrm{K}$ is applied topically prior to TPA, expression and activities of ODC are inhibited dose-dependently (Lee et al., 2005a). In addition, compound $\mathrm{K}$ given prior to each topical dose of TPA markedly lowered the number of papillomas in mouse skin induced by 7,12-dimethylbenz(a)anthracene. Thus, COX-2 inhibition is an essential mechanistic pathway for tumor inhibition by compound $\mathrm{K}$ (Lee et al., 2005a). Rg3 is also shown to inhibit expression of COX-2 in TPA-stimulated mouse skin. Rg3 also exerts potent inhibitory effects on the activation of AP-1 responsible for c-jun and c-fos oncogenic transactivation (Keum et al., 2003). P. notoginseng extracts have been shown to reduce significantly the levels of serum TGF- $\beta 1$, TNF- $\alpha$, and IL- 6 in a hepatic fibrosis model (induced by carbon tetrachloride) in Sprague-Dawley rats (Peng et al., 2009).

\section{INHIBITION OF Wnt/ $\beta$-CATENIN SIGNALING}

Colorectal cancers are mostly initiated by aberrant activation of the Wnt/ $\beta$-catenin signaling pathway (Kraus et al., 1994). The ginsenoside Rg3 has been shown to inhibit cell proliferation and viability of cancer cells in vitro by blocking nuclear translocation of the $\beta$-catenin protein and hence inhibiting $\beta$ catenin/Tcf transcriptional activity. Allelic deletion of the oncogenic $\beta$-catenin in HCT116 cells renders the cells more sensitive to $\mathrm{Rg} 3$-induced growth inhibition. In a xenograft colon cancer model, Rg3 effectively inhibits the growth of tumors derived from the colon cancer cell line HCT116. Histologic examination revealed that $\mathrm{Rg} 3$ inhibits cancer cell proliferation, decreases PNCA expression and diminishes nuclear staining intensity of $\beta$-catenin (He et al., 2011).

\section{INHIBITION OF HYPOXIA-INDUCIBLE FACTOR-1}

Hypoxia-inducible factor-1 (HIF-1) activates the transcription of genes that are involved in crucial aspects of cancer biology, including angiogenesis, cell survival, glucose metabolism and invasion. Intratumoral hypoxia and genetic alterations can lead to HIF- $1 \alpha$ overexpression, which has been associated with increased patient mortality in several cancer types. In both Hep3B cancer and HEK293 immortalized normal cell lines, aqueous extract of Korean red ginseng (KRGW) attenuates the expression of hypoxiainduced genes without apparent cytotoxicity (Choi et al., 2011). Mechanistically, KRGW does not affect the synthesis, degradation, and translocation of HIF-1 in hypoxia. Interestingly, the authors found that KRGW represses the transcriptional activity of HIF1 by interfering with the dimerization between HIF- $1 \alpha$ and aryl hydrocarbon receptor nuclear translocator.

\section{ACTIVATION OF Nrf2 PATHWAY}

Nuclear erythroid 2 p45-related factor 2 (Nrf2) is a redox-sensitive basic leucine zipper transcription factor involved in the transcriptional regulation of many antioxidant genes. Nrf2 is inhibited in the cytoplasm by the anchor protein Kelch-like ECH-associated protein-1 (Keap1), a cytosolic protein that inhibits Nrf2 signaling by promoting proteasomal degradation of $\mathrm{Nrf} 2$. In the presence of 
oxidative stress or chemical inducers, Nrf2 is released from Keap1 inhibition, translocates to the nucleus, and binds to antioxidant response element (ARE) consensus sequences. Activation of Nrf2 by chemopreventive agents influences expression of anti-oxidative phase-I and phase-II enzymes including heme oxygenase-1 (HO1), NADPH quinone oxidoreductase-1 (NQO1), and glutathione (Lee and Johnson, 2004). An aqueous extract of wild ginseng has been shown to increase expression of GSTA2, GSTA3, and GSMT2 via an NRF-ARE pathway (Saw et al., 2010). Korean RGE has been shown induce HO-1 by NRF-ARE pathway in rat pheocromocytoma cells (Park et al., 2010b). Ginsenoside Rb1 exhibits protection against 6-hydroxydopamine induced oxidative stress in human neuroblastoma SH-SY5Y cells (Hwang and Hye, 2010).

\section{INHIBITION OF hTERT}

The human telomerase reverse transcriptase (hTERT), the active subunit of telomerase is activated in cancer cells and prevents telomere shortening, thus inhibiting of apoptotic processes. The inhibition of hTERT is an additional mechanism by which ginsenosides can induce cell death in cancer cells. Compound $\mathrm{K}$ is known to inhibit cell proliferation by inducing apoptosis and cell cycle arrest at the G1 phase (Kang et al., 2005). Compound K treatment reduces telomerase activity and downregulates the (hTERT) gene, resulting in the decreased expressions of its protein, and of the c-Myc and Sp1 proteins (transcription factors of hTERT) in U937 leukemia cells (Kang et al., 2006). Also, the hot water extract of Korean red ginseng causes significant inhibition on the growth of U937 leukemia cells which is associated with the inhibition of hTERT expression (Park et al., 2009).

\section{INHIBITION OF MULTIDRUG RESISTANCE}

A major difficulty in the treatment of human malignancies is the development of broad anticancer drug resistance by tumor cells. This phenomenon has been termed "multidrug resistance" (MDR). Among all ginsenosides, $20(S)-\operatorname{Rg} 3$ is found to have the most potent inhibitory activity on MDR. Rg3 reverses MDR in drug-resistant human fibrocarcinoma KBV20C cells specifically and effectively in a dose-dependent manner (Park et al., 2005). Several ginsenosides, including 20(S)-Rh2, have been shown to inhibit the transport function of P-glycoprotein and increase sensitivity to cancer chemotherapeutics in resistant cells ( $\mathrm{Li}$ et al., 2008).

\section{CLINICAL STUDIES}

Though many ginsenosides show a clear anticancer activity in cancer cell lines or xenograft tumor models, it is imperative to observe their effects in human subjects. Two Chinese studies have found that ginseng works synergistically with chemotherapy: One study examined 176 digestive tract cancer cases and found reduced toxic effects ( $\mathrm{Li}, 1992)$. The other study involved a randomized trial of 63 stomach cancer cases (Lin et al., 1995). Both studies found improved immune function. Five studies examined the effectiveness of ginseng in relation to cancer mortality as an end point. Two were case-control studies (Yun and Choi, 1990; Rebbeck et al., 2007); two were prospective studies (Yun and Choi, 1998; Cui et al., 2006) while one was a randomized trial (Suh et al., 2002).
The randomized study conducted in Korea found a 5-year disease free survival and significantly longer survival time among stage III gastric cancer patients during postoperative chemotherapy.

One of the case-control studies found no significant association between breast cancer risk and ginseng (Rebbeck et al., 2007). However, the case control study conducted in a Korean population reported a significant protective effect against total cancer risk (Yun and Choi, 1990). Even among subjects who consumed ginseng only one to three times a year, a protective effect was found. The protective effect was found among a variety of cancer types with both cohort studies reporting a significant protective effect.

Overall, fairly consistent protective effect of ginseng has been found against cancer risk and cancer mortality. Also, an improved immune function may be possible when ginseng is administered during chemotherapy. A protective effect might already be possible with minimal consumption of ginseng (one to three times a year; Yun and Choi, 1990). However, some of the above studies (Li, 1992; Lin et al., 1995) used compound Chinese herbal preparations containing ginseng extracts. It, therefore, becomes difficult to actually attribute the chemopreventive properties of the formulation specifically to a particular class of compounds, i.e., ginsenosides.

Also, sometimes conflicting and confusing results come to the fore. As an example, a large case-control study and a small cohort study have both suggested that ginseng use is associated with a $60-70 \%$ reduction in gastric cancer risk in Korean populations. However, when the study was attempted to be duplicated in a large prospective cohort study of Chinese women, no association between ginseng intake and gastric cancer risk was found (Kamangar et al., 2007).

A randomized, double-blind clinical study to investigate whether American ginseng might help cancer-related fatigue, suggests that American ginseng, at a dose of $750 \mathrm{mg} /$ day, does not provide any benefit over that seen with a placebo However, the two highest doses of ginseng ( 1000 and $2000 \mathrm{mg}$ /day) did appear to decrease fatigue more than a placebo, as measured by various scales of fatigue, vitality, and well-being. Data suggested that the higher doses of ginseng might be necessary for alleviating cancer-related fatigue (Barton et al., 2010).

In a randomized, double-blinded, placebo-controlled trial on 643 chronic atrophic gastritis patients in China, RGE powder was administered orally to each patient per week for 3 years and followed up for 8 years. The development of different types of cancers in the red ginseng subjects was compared to that of a placebo group and it was seen that administration of RGE powder for 3 years exerted significant preventive effects on the incidence of non-organ-specific human cancers in males (Yun et al., 2010).

\section{CONCLUSION}

Pre-clinical and clinical studies indicate that ginsenosides can be effective and safe anticancer agents. Ginsenoside saponins exhibit diverse molecular mechanisms of action, regulating most known modulators of carcinogenesis. Because of various mechanisms of cell death employed by ginsenosides, it may be difficult for cells to develop resistance to ginsenoside-induced cell death. Furthermore, the ability to kill tumor cells and relative non-toxicity to 
normal cells make ginsenosides attractive candidates for drug development. However, the diversity in both chemical structure and biological activity leads to several challenges. Different species of ginseng have different saponin profiles. Also the mode of preparation of the plant extracts affects the quantity of its active anticancer principles. For example, heat treated red ginseng has a higher quantity of $\mathrm{Rg} 3, \mathrm{Rh} 2$, and PPD. As a result, it is often difficult to standardize studies and varying results have been obtained. What is needed today is a systematic study of a series of related compounds in established, well characterized cancer models to ascertain the relationship between the structure and anticancer activity of these compounds. These data should then be used to develop novel semi-synthetic ginsenosides with improved efficacy, pharmacokinetics, and bioavailability profiles. The use of modern combinatorial libraries and high throughput screening techniques coupled with an in-depth understanding of the molecular mechanisms underlying ginseng's biological activities is necessary to harness the full benefits of ginseng and ginseng products in treatment and prevention of cancer and other chronic diseases.

\section{REFERENCES}

Aggarwal, B. B., and Shishodia, S. (2006). Molecular targets of dietary agents for prevention and therapy of cancer. Biochem. Pharmacol. 71, 1397-1421.

Assinwe, V., Baum, B., Gagnon, D., and Arnason, J. (2003). Phytochemistry of wild populations of Panax quinquefolium L. (North American ginseng). J. Agric. Food Chem. 51, 4549-4553.

Atopkina, L. N., Malinovskaya, G. V., Elyakov, G. B., Uvarova, N. I., Woerdenbag, H. J., Koulman, A., Pras, N., and Potier, P. (1999). Cytotoxicity of natural ginseng glycosides and semisynthetic analogues. Planta Med. 65, 30-34.

Attele, A. S., Wu, J. A., and Yuan, C. S. (1999). Ginseng pharmacology: multiple constituents and multiple actions. Biochem. Pharmacol. 58, 1685-1693.

Barton, D. L., Soori, G. S., Bauer, B. A., Sloan, J. A., Johnson, P. A., Figueras, C., Duane, S., Mattar, B., Liu, H., Atherton, P. J., Christensen, B., and Loprinzi, C. L. (2010). Pilot study of Panax quinquefolius (American ginseng) to improve cancer-related fatigue: a randomized, double-blind, dose-finding evaluation: NCCTG trial N03CA. Support. Care Cancer 18, 179-187.

Bespalov, V. G., Alexandrov, V. A., Limarenko, A. Y., Voytenkov, B. O., Okulov, V. B., Kabulov, M. K., Peresunko, A. P., Slepyan, L. I., and Davydov, V. V. (2001). Chemoprevention of mammary, cervix and nervous system carcinogenesis in animals using cultured Panax ginseng drugs and preliminary clinical trials in patients with precancerous lesions of the esophagus and endometrium. J. Korean Med. Sci. 16, S42-S53.

Carlson, A. (1986). Ginseng: America's botanical drug connection to the orient. Econ. Bot. 40, 233-249.

Chang, Y. S., Seo, E. K., Gyllenhaal, C., and Block, K. I. (2003). Panax ginseng: a role in cancer therapy? Integr. Cancer Ther. 2, 13-33. Lin, N. H., and Tzen, J. T. (2009). sides and their inhibitory potency on $\mathrm{Na}^{+} / \mathrm{K}^{+}$-ATPase activity. Acta. Pharmacol. Sin. 30, 61-69.

Cheng, C. C., Yang, S. M., Huang, C. Y., Chen, C. J., Chang, W. M., and Hsu, S. L. (2005). Molecular mechanisms of ginsenoside Rh2-mediated G1 growth arrest and apoptosis in human lung adenocarcinoma A549 cells. Cancer Chemother. Pharmacol. 55, 531-540.

Choi, K., and Choi, C. (2009). Proapoptotic ginsenosides compound $\mathrm{K}$ and Rh2 enhance FAS-induced cell death of human astrocytoma cells through distinct apoptotic signaling pathways. Cancer Res. Treat. 41, 36-44.

Choi, Y. J., Choi, H., Cho, C. H., and Park, J. W. (2011). Red ginseng deregulates hypoxia-induced genes by dissociating the HIF-1 dimer. $J$. Nat. Med. 65, 344-352.

Choo, M. K., Sakurai, H., Kim, D. H., and Saiki, I. (2008). A ginseng saponin metabolite suppresses tumor necrosis factor-alphapromoted metastasis by suppressing nuclear factor-kappaB signaling in
Chen, J. Y., Chung, T. Y., Li, F. Y., Effect of sugar positions in ginseno-

\section{AUTHOR PROFILE}

Ruiwen Zhang, MD, PhD, DABT, AAAS Fellow, is Professor of Pharmaceutical Sciences at the Texas Tech University Health Sciences Center at Amarillo, Texas, USA. He has extensive experience in translational biomedical and pharmaceutical research, particularly in the areas of clinical pharmacology and therapeutics, biotechnology, cancer therapy and prevention, and pharmaceutical and toxicological researches.

\section{ACKNOWLEDGMENTS}

We thank the members of our laboratories for their contributions to the research projects that were cited in this review. We apologize for not being able to cite all the publications in the field, due to limitation of the length of the review. Ruiwen Zhang was supported by NIH grants R01 CA112029 and R01 CA121211. Ming-Hai Wang was supported by NIH grant R01 CA91980. Hui Wang was supported by grants from One Hundred Talents Program of the Chinese Academy of Sciences and the National Nature Science Foundation (81125020, 91029715 and 31070680). We thank Mr. S. Voruganti for reading the manuscript.

murine colon cancer cells. Oncol. Rep. 19, 595-600.

Christensen, L. P. (2009). Ginsenosides chemistry, biosynthesis, analysis, and potential health effects. $A d v$. Food Nutr. Res. 55, 1-99.

Coates, P. B., Blackman, M., and Crag, G. (2005). "Asian ginseng, (Panax ginseng)," in Encyclopedia of Dietary Supplements, eds J. D. White, P. M. Coates, and M. Blackman (New York: Marcel Dekker Press), 265-277.

Court, W. (2000). Ginseng: The Genus Panax. New York: Harwood Academic Publishers.

Cui, Y., Shu, X. O., Gao, Y. T., Cai, H., Tao, M. H., and Zheng, W. (2006). Association of ginseng use with survival and quality of life among breast cancer patients. Am. J. Epidemiol. 163 645-653.

Deryugina, E., and Quigley, J. (2006). Matrix metalloproteinases and tumor metastasis. Cancer Metastasis Rev. 25, 9-34.

Dharmananda, S. (2002). The nature of ginseng: from traditional use to modern research. HerbalGram 54, 341-354.

Dougherty, U., Mustafi, R., Wang, Y., Musch, M. W., Wang, C. Z., Konda, V. J., Kulkarni, A., Hart, J., Dawson, G., Kim, K. E., Yuan, C. S., Chang, E. B., and Bissonnette, M. (2011). American ginseng suppresses Western diet-promoted tumorigenesis in model of inflammation-associated colon cancer: role of EGFR. BMC Complement. Altern. Med. 11, 111. doi:10.1186/1472-6882-11-111

Elliott, A., and Reiners, J. (2008). Suppression of autophagy enhances the cytotoxicity of the DNA-damaging aromatic amine p-anilinoaniline. Toxicol. Appl. Pharmacol. 232, 169-179.

Fiske, J. L., Fomin, V. P., Brown, M. L., Duncan, R. L., and Sikes, R. A. (2006). Voltage-sensitive ion channels and cancer. Cancer Metastasis Rev. 25, 493-500.

Foster, S. (1996a). Panax Ginseng. Austin, TX: American Botanical Council.

Foster, S. (1996b). Panax Quinquefolius. Austin, TX: American Botanical Council.

Fujimoto, J., Sakaguchi, H., Aoki, I., Toyoki, H., Khatun, S., and Tamaya, T. (2001). Inhibitory effect of ginsenoside- $\mathrm{Rb} 2$ on invasiveness of uterine endometrial cancer cells to the basement membrane. Eur. J. Gynaecol. Oncol. 22, 339-341.

Grafton, E. (2002). "The history, the mystery of ginseng," in West Virginia Wildlife Magazine (South Charleston: West Virginia Division of Natural Resources), Summer Volume.

Guo, L., Song, L., Wang, Z., Zhao, W., Mao, W., and Ming, Y. (2009). Panaxydol inhibits the proliferation and induces the differentiation of human hepatocarcinoma cell line HepG2. Chem. Biol. Interact. 181, 138-143.

Ha, Y. W., Ahn, K. S., Lee, J. C., Kim, S. H., Chung, B. C., and Choi, M. H. (2010). Validated quantification for selective cellular uptake of ginsenosides on MCF-7 human breast cancer cells by liquid chromatographymass spectrometry. Anal. Bioanal. Chem. 396, 3017-3025. 
Han, H. J., Yoon, B. C., Lee, S. H., Park, S. H., Park, J. Y., Oh, Y. J., and Lee, Y. J. (2002). Ginsenosides inhibit EGFinduced proliferation of renal proximal tubule cells via decrease of $\mathrm{c}$-fos and c-jun gene expression in vitro. Planta Med. 68, 971-974.

Hasegawa, H., Sung, J. H., Matsumiya, S., and Uchiyama, M. (1996). Main ginseng saponin metabolites formed by intestinal bacteria. Planta Med. 62, 453-457.

Hasegawa, H., Sung, J. H., Matsumiya, S., Uchiyama, M., Inouye, Y., Kasai, R., and Yamasaki, K. (1995). Reversal of daunomycin and vinblastine resistance in multidrug-resistant P388 leukemia in vitro through enhanced cytotoxicity by triterpenoids. Planta Med. 61, 409-413.

He, B. C., Gao, J. L., Luo, X, Luo, J, Shen, J., Wang, L., Zhou, Q., Wang, Y. T., Lu, H. H., Haydon, R. C., Wang, C. Z., Du, W., Yuan, C. S., He, T. C., and Zhang, B. Q. (2011). Ginsenoside Rg3 inhibits colorectal tumor growth through the downregulation of $\mathrm{Wnt} / \beta$-catenin signaling. Int. J. Oncol. 38, 437-445.

Hemmerly, T. E. (1977). A ginseng farm in Lawrence County, Tennessee. Econ. Bot. 31, 160-162.

Hwang, Y. P., and Hye, G. J. (2010). Ginsenoside Rb1 protects against 6-hydroxydopamine-induced oxidative stress by increasing heme oxygenase-1 expression through an estrogen receptorrelated PI3K/Akt/Nrf2-dependent pathway in human dopaminergic cells. Toxicol. Appl. Pharmacol. 242, $18-28$

Jeong, A., Lee, H. J., Jeong, S. J., Lee, H. J., Lee, E. O., Bae, H., and Kim, S. H. (2010). Compound $\mathrm{K}$ inhibits basic fibroblast growth factor-induced angiogenesis via regulation of p38 mitogen activated protein kinase and akt in human umbilical vein endothelial cells. Biol. Pharm. Bull. 33, 945-950.

Jeong, S. M., Lee, J. H., Kim, J. H., Lee, B. H., Yoon, I. S., and Kim, D. H. (2004). Stereospecificity of ginsenoside Rg3 action on ion channels. Mol. Cells 18, 383-389.

Jung, J. S., Kim, D. H., and Kim, H. S. (2010a). Ginsenoside Rhl suppresses inducible nitric oxide synthase gene expression in IFNgamma-stimulated microglia via modulation of JAK/STAT and ERK signaling pathways. Biochem. Biophys. Res. Commun. 397, 323-328.

Jung, J. S., Shin, J., Park, E. M., Lee, J. E., Kang, Y. S., Min, S. W., Kim, D. H., Hyun, J. W., Shin, C. Y., and Kim, H. S. (2010b). Anti-inflammatory mechanism of ginsenoside Rh1 in lipopolysaccharide-stimulated microglia: critical role of the protein kinase A pathway and hemeoxygenase-1 expression. J. Neurochem. 115, 1668-1680.

Jung, S. H., Woo, M. S., Kim, S. Y., Kim, W. K., Hyun, J. W., Kim, E. J., Kim, D. H., and Kim, H. S. (2006). Ginseng saponin metabolite suppresses phorbol ester-induced matrix metalloproteinase- 9 expression through inhibition of activator protein-1 and mitogen-activated protein kinase signaling pathways in human astroglioma cells. Int. J. Cancer 118, 490-497.

Kamangar, F., Gao, Y. T., Shu, X. O., Kahkeshani, K., Ji, B. T., Yang, G., Li, H. L., Rothman, N., Chow, W. H., and Zheng, W. (2007). Ginseng intake and gastric cancer risk in the Shanghai women's health study cohort. Cancer Epidemiol. Biomarkers Prev. 16, 629-630.

Kang, J. H., Song, K. H., Woo, J. K., Park, M. H., Rhee, M. H., Choi, C., and Oh, S. H. (2011). Ginsenoside Rp1 from Panax ginseng exhibits anti-cancer activity by down-regulation of the IGF-1R/Akt pathway in breast cancer cells. Plant Foods Hum. Nutr. 66, 298-305.

Kang, K. A., Kim, Y., Kim, S. U., Chae, S., Koh, Y. S., Kim, H. S., Choo, M. K., Kim, D. H., and Hyun, J. W. (2005). G1 phase arrest of the cell cycle by a ginseng metabolite, compound K, in U937 human monocytic leukamia cells. Arch. Pharm. Res. 28, 685-690.

Kang, K. A., Lee, K. H., Chae, S., Kim, J. K., Seo, J. Y., Ham, Y. H., Lee, K. H., Kim, B. J., Kim, H. S., Kim, D. H., and Jin, W. H. (2006). Inhibition of telomerase activity in U937 human monocytic leukemia cells by compound $\mathrm{K}$, a ginseng saponin metabolite. Biotechnol. Bioprocess Eng. 11, 7-12.

Kasai, R., Besso, H., Tanaka, O., Saruwatari, Y., and Fuwa, T. (1983). Saponins of red ginseng. Chem. Pharm. Bull. 31, 2120-2125.

Keum, Y. S., Han, S. S., Chun, K. S., Park, K. K., Park, J. H., Lee, S. K., and Surh, Y. J. (2003). Inhibitory effects of the ginsenoside $\mathrm{Rg} 3$ on phorbol ester-induced cyclooxygenase2 expression, NF-kappaB activation and tumor promotion. Mutat. Res. 523-524, 75-85.

Kim, A. D., Kang, K. A., Zhang, R., Lim, C. M., Kim, H. S., Kim, D. H., Jeon, Y. J., Lee, C. H., Park, J., Chang, W. Y., and Hyun, J. W. (2010a). Ginseng saponin metabolite induces apoptosis in MCF-7 breast cancer cells through the modulation of AMPactivated protein kinase. Environ. Toxicol. Pharmacol. 30, 134-140.

Kim, S. M., Lee, S. Y., Cho, J., Choi, S. S., Yun, Y. P., Yoo, H. S., Yoon, D. Y., Oh, K. W., Han, S. B., and Hong, J. T. (2010b). Combination of ginsenoside Rg3 with docetaxel enhances the susceptibility of prostate cancer cells via inhibition of NF-kappaB. Eur. J. Pharmacol. 631, 1-9.

Kim, B. H., Lee, Y. H., Park, T. Y., Kim, H. B., Rhee, M. H., and Cho, J. Y. (2009). Ginsenoside Rp1, a ginsenoside derivative, blocks lipopolysaccharide-induced interleukin-1beta production via suppression of the NF-kappaB pathway. Planta Med. 75, 321-326.

Kim, H. S., Lee, E. H., Ko, S. R., Choi, K. J., Park, J. H., and Im, D. S. (2004). Effects of ginsenosides Rg3 and $\mathrm{Rh} 2$ on the proliferation of prostate cancer cells. Arch. Pharm. Res. 27, 429-435.

Kim, J. Y., Yu, S. J., Oh, H. J., Lee, J. Y., Kim, Y., and Sohn, J. (2011). Panaxydol induces apoptosis through an increased intracellular calcium level, activation of JNK and p38 MAPK and NADPH oxidase-dependent generation of reactive oxygen species. Apoptosis 16, 347-358.

Kim, T. H., Lee, Y. S, Cho, C. K., Park, S., Choi, S. Y., and Yool, S. Y. (1996). Protective effect of ginseng on radiation-induced DNA double strand breaks and repair in murine lymphocytes. Cancer Biother. Radiopharm. 11, 267-272.

Kim, Y. K., Guo, Q., and Packer, L. (2002). Free radical scavenging activity of red aqueous extracts. Toxicology 172, 149-156.

Kim, Y. S., Kim, D. S., and Kim, S. I. (1998). Ginsenoside Rh2 and $\mathrm{Rh} 3$ induce differentiation of HL60 cells into granulocytes: modulation of protein kinase $\mathrm{C}$ isoforms during differentiation by ginsenoside Rh2. Int. J. Biochem. Cell Biol. 30, 327-338.

King, M. L., and Murphy, L. (2006). The mechanism of action of ginsenginduced inhibition of human colon cancer cell HCT116 proliferation is influenced by p21 status. Proc. Am. Assoc. Cancer Res. 47.

King, M. L., and Murphy, L. (2010). Role of cyclin inhibitor protein p21 in the inhibition of HCT116 human colon cancer cell proliferation by American ginseng (Panax quinquefolius) and its constituents. Phytomedicine 17, 261-268.

Kitts, D. D., Wijewickreme, A. N., and $\mathrm{Hu}, \mathrm{C}$. (2000). Antioxidant properties of a North American ginseng extract. Mol. Cell. Biochem. 203, $1-10$.

Ko, H., Kim, Y. J., Park, J. S., Park, J. H., and Yang, H. O. (2009). Autophagy inhibition enhances apoptosis induced by ginsenoside $\mathrm{Rk} 1$ in hepatocellular carcinoma cells. Biosci. Biotechnol. Biochem. 73, 2183-2190

Konoshima, T., Takasaki, M., Ichiishi, E., Murakami, T., Tokuda, H., Nishino, H., Duc, N. M., Kasai, R., and Yamasaki, K. (1999). Cancer chemopreventive activity of majonoside-R2 from Vietnamese ginseng, Panax vietnamensis. Cancer Lett. 147, 11-16.

Kraus, C., Liehr, T., Hülsken, J., Behrens, J., Birchmeier, W., Grzeschik, K. H. and Ballhausen, W. G. (1994). Localization of the human beta-catenin gene (CTNNB1) to $3 \mathrm{p} 21$ : a region implicated in tumor development. Genomics 23, 272-274.

Langenhan, J. M., Peters, N. R., Guzei, I. A., Hoffmann, F. M., and Thorson, J. S. (2005). Enhancing the anticancer properties of cardiac glycosides by neoglycorandomization. Proc. Natl. Acad. Sci. U.S.A. 102, 12305-12310.

Lee, I. K., Kang, K. A., Lim, C. M., Kim, K. C., Kim, H. S., Kim, D. H., Kim, B. J., Chang, W. Y., Choi, J. H., and Hyun, J. W. (2010). Compound K, a metabolite of ginseng saponin, induces mitochondria-dependent and caspase-dependent apoptosis via the generation of reactive oxygen species in human colon cancer cells in human colon cancer cells. Int. J. Mol. Sci. 11, 4916-4931.

Lee, J., Lee, E., Kim, J., Lee, J., Yoo, J., and Kim, B. (2009a). Studies on absorption, distribution and metabolism of ginseng in humans after oral administration. J. Ethnopharmacol. 122, 143-148.

Lee, S. Y., Kim, G. T, Roh, S. H., Song, J. S., Kim, H. J., and Hong, S. S. (2009b). Proteomic analysis of the anti-cancer effect of 20Sginsenoside $\mathrm{Rg} 3$ in human colon cancer cell lines. Biosci. Biotechnol. Biochem. 73, 811-816.

Lee, J., and Zhao, Y. (2009). Current evaluation of the millennium phytomedicine-ginseng (I): etymology, pharmacognosy, phytochemistry, market and regulations. Curr. Med. Chem. 16, 2475-2484.

Lee, J. M., and Johnson, J. A. (2004). An important role of NRF2-ARE pathway in the cellular defense mechanism. J. Biochem. Mol. Biol. 37, 139-143.

Lee, J. Y., Shin, J. W., Chun, K. S., Park, K. K., Chung, W. Y., Bang, 
Y. J., Sung, J. H., and Surh, Y. J. (2005a). Antitumor promotional effects of a novel intestinal bacterial metabolite (IH-901) derived from the protopanaxadiol-type ginsenosides in mouse skin. Carcinogenesis 26, 359-367.

Lee, T. K., Johnke, R. M., Allison, R. R., O'Brien, K. F., and Dobbs, L. J. (2005b). Radioprotective potential of ginseng. Mutagenesis 20, 237-243.

Lee, K. Y., Lee, Y. H., Kim, S. I., Park, J. H., and Lee, S. K. (1997). Ginsenoside-Rg5 suppresses cyclin e-dependent protein kinase activity via up-regulating p21 (Cip/WAF1) and down-regulating cyclin $\mathrm{E}$ in SK-HEP-1 cells. Anticancer Res. 17, 1067-1072.

Lee, Y. H., Kim, S. I., Lee, S. K., Chung, H. Y., and Kim, K. W. (1993). "Differentiation mechanism of ginsenosides in cultured murine F9 teratocarcinoma stem cells," in Proceedings of the 6th Int ernational Ginseng Symposium, Seoul, 127-131.

Lee, Y. J., Kim, H. Y., Kang, K. S., Lee, J. G., Yokozawa, T., and Park, J. H. (2008). The chemical and hydroxyl radical scavenging activity changes of ginsenoside-Rb-1 by heat processing. Bioorg. Med. Chem. Lett. 18, 4515-4520.

Leung, K. W., Cheung, L. W., Pon, Y. L., Wong, R. N., Mak, N. K., Fan, T. P., Au, S. C., Tombran-Tink, J., and Wong, A. S. (2007). Ginsenoside Rb1 inhibits tube-like structure formation of endothelial cells by regulating pigment epithelium-derived factor through the estrogen beta receptor. Br. J. Pharmacol. 152, 207-215.

Li, B., Zhao, J., Wang, C. Z., Searle, J., He, T. C., Yuan, C. S., and Du, W. (2011). Ginsenoside Rh2 induces apoptosis and paraptosis-like cell death in colorectal cancer cells through activation of p53. Cancer Lett. 301, 185-192.

Li, N. Q. (1992). Clinical and experimental study on shen-qi injection with chemotherapy in the treatment of malignant tumor of digestive tract. Zhongguo Zhong Xi Yi Jie He Za Zhi 12, 588-592.

Li, Q. F., Shi, S., Liu, Q. R., Tang, J., Song, J., and Liang, Y. (2008). Anticancer effects of ginsenoside Rgl, cinnamic acid, and tanshinone IIA in osteosarcoma MG-63 cells: nuclear matrix downregulation and cytoplasmic trafficking of nucleophosmin. Int. J. Biochem. Cell Biol. 40, 1918-1929.

Li, W., Gu, C., Zhang, H., Awang, D. V., Fitzloff, J. F., Fong, H. H., and van Breemen, R. B. (2000). Use of high-performance liquid chromatography-tandem mass spectrometry to distinguish Panax ginseng C. A. Meyer (Asian ginseng) and Panax quinquefolius L. (North American ginseng). Anal. Chem. 72, 5417-5422.

Li, W., Liu, Y., Zhang, J. W., Ai, C. Z., Xiang, N., Liu, H. X., and Yang, L. (2009). Anti-androgen-independent prostate cancer effects of ginsenoside metabolites in vitro: mechanism and possible structure-activity relationship investigation. Arch. Pharm. Res. 32, 49-57.

Lin, S. Y., Liu, L. M., and Wu, L. C. (1995). Effects of Shenmai injection on immune function in cancer patients after chemotherapy. Zhongguo Zhong Xi Yi Jie He Za Zhi 15, 451-453.

Liu, C. X., and Xiao, P. (1992). Recent advances on ginseng research in China. J. Ethnopharmacol. 36, 27-38.

Liu, W. J., Tang, H. T., Jia, Y. T., Ma, B., Fu, J. F., Wang, Y., Lv, K. Y., and Xia, Z. F. (2010). Notoginsenoside R1 attenuates renal ischemiareperfusion injury in rats. Shock 34 , 314-320.

Liu, W. K., Xu, X. S., and Che, C. T. (2000). Anti-proliferative effect of ginseng saponins on human prostate cancer cell line. Life Sci. 67, 1297-1306.

Lui, J. H., and Staba, E. J. (1980). The ginsenosides of various ginseng plants and selected products. J. Nat. Prod. 43, 340-346.

Luo, X., Wang, C. Z., Chen, J., Song, W. X., Luo, J., Tang, N., He, B. C., Kang, Q., Wang, Y., Du, W., He, T. C., and Yuan, C. S. (2008). Characterization of gene expression regulated by American ginseng and ginsenoside $\mathrm{Rg} 3$ in human colorectal cancer cells. Int. J. Oncol. 32, 975-983.

Mochizuki, M., Yoo, Y. C., Matsuzawa, K., Sato, K., Saiki, I., Tono-Oka, S., Samukawa, K., and Azuma, I. (1995). Inhibitory effect of tumor metastasis in mice by saponins, ginsenoside$\mathrm{Rb} 2,20(\mathrm{R})$ - and 20(S)-ginsenosideRg3, of red ginseng. Biol. Pharm. Bull. 18, 1197-1202.

Nakamura, S., Sugimoto, S., Matsuda, H., and Yoshikawa, M. (2007). Medicinal flowers. XVII. New dammarane-type triterpene glycosides from flower buds of American ginseng, Panax quinquefolium L. Chem. Pharm. Bull. 55, 1342-1348.

Nicholson, D. W., and Thornberry, N. A. (1997). Caspases: killer proteases. Trends Biochem. Sci. 22, 299-306.

Odashima, S., Ota, T., FujikawaYamamoto, K., and Abe, H. (1989). Induction of phenotypic reverse transformation by plant glycosides in cultured cancer cells. Gan To Kagaku Ryoho 16, 1483-1489.

Oh, M., Choi, C. Y., Choi, S., Chung, H., Kim, K., Kim, S., Kim, D. K., and Kim, N. D. (1999). Antiproliferating effects of ginsenoside Rh2 on MCF-7 human breast cancer cells. Int. J. Oncol. 14, 869-875.

Overholtzer, M., Mailleux, A. A., Mouneimne, G., Normand, G., Schnitt, S. J., King, R. W., Cibas, E. S., and Brugge, J. S. (2007). A nonapoptotic cell death process, entosis, that occurs by cell-in-cell invasion. Cell 131, 966-979.

Park, E. K., Lee, E. J., Lee, S. H., Koo, K. H., Sung, J. Y., Hwang, E. H., Park, J. H., Kim, C. W., Jeong, K. C., Park, B. K., and Kim, Y. N. (2010a). Induction of apoptosis by the ginsenoside $\mathrm{Rh} 2$ by internalization of lipid rafts and caveolae and inactivation of Akt. Br. J. Pharmacol. 160, 1212-1223.

Park, S. H., Jang, J. H., Chen, C. Y., Na, H. K., and Surh, Y. J. (2010b). A formulated red ginseng extract rescues PC12 cells from PCB-induced oxidative cell death through Nrf2mediated upregulation of heme oxygenase- 1 and glutamate cysteine ligase. Toxicology 278, 131-139.

Park, J., and Cho, J. Y. (2009). Antiinflammatory effects of ginsenosides from Panax ginseng and their structural analogs. Afr. J. Biotechnol. 8, 3682-3690.

Park, J. A., Lee, K. Y., Oh, Y. J., Kim, K. W., and Lee, S. K. (1997). Activation of caspase- 3 protease via a $\mathrm{Bcl}$-2-insensitive pathway during the process of ginsenoside Rh2-induced apoptosis. Cancer Lett. 121, 73-81.

Park, J. D., Rhee, D. K., and Yui, H. L. (2005). Biological activities and chemistry of saponins from Panax ginseng C. A. Meyer. Phytochem. Rev. 4, 159-175.

Park, M. T., Cha, H. J., Jeong, J. W., Kim, S. I., Chung, H. Y., Kim, N. D., Kim, O. H., and Kim, K. W. (1999). Glucocorticoid receptor-induced downregulation of MMP-9 by ginseng components, $\mathrm{PD}$ and $\mathrm{PT}$ contributes to inhibition of the invasive capacity of HT1080 human fibrosarcoma cells. Mol. Cells 9, 476-483.

Park, S., Yeo, M., Jin, J. H., Lee, K. M., Kim, S. S., Choi, S. Y., and Hahm, K. B. (2007). Inhibitory activities and attenuated expressions of 5LOX with red ginseng in Helicobacter pylori-infected gastric epithelial cells. Dig. Dis. Sci. 52, 973-982.

Park, S. E., Park, C., Kim, S. H., Hossain, M. A., Kim, M. Y., Chung, H. Y., Son, W. S., Kim, G. Y., Choi, Y. H., and Kim, N. D. (2009). Korean red ginseng extract induces apoptosis and decreases telomerase activity in human leukemia cells. J. Ethnopharmacol. 121, 304-312.

Peng, X. D., Dai, L. L., Huang, C. Q., He, C. M., Yang, B., and Chen, L. J. (2009). Relationship between antifibrotic effect of Panax notoginseng saponins and serum cytokines in rat hepatic fibrosis. Biochem. Biophys. Res. Commun. 388, 31-34.

Peralta, E. A., Murphy, L. L., Minnis, J., Louis, S., and Dunnington, G. L. (2009). American ginseng inhibits induced COX-2 and NFKB activation in breast cancer cells. J. Surg. Res. 157, 261-267.

Popovich, D. G., and Kitts, D. (2002). Structure-function relationship exists for ginsenosides in reducing cell proliferation and inducing apoptosis in the human leukemia (THP-1) cell line. Arch. Biochem. Biophys. 406, 1-8.

Popovich, D. G., and Kitts, D. (2004). Ginsenosides 20(S)protopanaxadiol and $\mathrm{Rh} 2$ reduce cell proliferation and increase subG1 cells in two cultured intestinal cell lines, Int-407 and Caco-2. Can. J. Physiol. Pharmacol. 82, 183-190.

Qi, L., Wang, C. Z., and Yuan, C. (2010). American ginseng: potential structure-function relationship in cancer chemoprevention. Biochem. Pharmacol. 80, 947-954.

Rebbeck, T. R., Troxel, A. B., and Norman, S. (2007). A retrospective casecontrol study of the use of hormonerelated supplements and association with breast cancer. Int. J. Cancer 120, 1523-1538.

Rhee, Y. H., Ahn, J., Choe, J., Kang, K. W., and Joe, C. (1991). Inhibition of mutagenesis and transformation by root extracts of Panax ginseng in vitro. Planta Med. 57, 121-125.

Sanada, S., Kondo, N., Shoji, J., Tanaka, O., and Shibata, S. (1974). Studies on the saponin of ginseng. I. Structures of ginsenoside-Ro, -Rb1, -Rc, and -Rd. Chem. Pharm. Bull. 22, $421-428$.

Saw, C. L., Wu, Q., and Kong, A. N. (2010). Anti-cancer and potential chemopreventive actions of ginseng by activating Nrf2 (NFE2L2) antioxidative stress/anti-inflammatory pathways. Chin. Med. 5, 37.

Shim, J. Y., Han, Y., Ahn, J. Y., Yun, Y. S., and Song, J. Y. (2007). Chemoprotective and adjuvant effects of immunomodulator ginsan in cyclophosphamide-treated normal and tumor bearing mice. Int. J. Immunopathol. Pharmacol. 20, 487-497.

Shin, Y. W., Bae, E. A., Han, M. J., and Kim, D. H. (2006). Metabolism 
of ginsenoside $\mathrm{Rg} 5$, a main constituent isolated from red ginseng, by human intestinal microflora and their antiallergic effect. J. Microbiol. Biotechnol. 16, 1791-1798.

Shinkai, K., Akedo, H., Mukai, M., Imamura, F., Isoai, A., Kobayashi, M., and Kitagawa, I. (1996). Inhibition of in vitro tumor cell invasion by ginsenoside Rg3. Jpn. J. Cancer Res. 87, 357-362.

Sperandio, S., Poksay, K., De Belle, I., Lafuente, M. J., Liu, B., Nasir, J., and Bredesen, D. E. (2004). Paraptosis: mediation by MAP kinases and inhibition by AIP-1/Alix. Cell Death Differ. 11, 1066-1075.

Suh, S. O., Kroh, M., Kim, N. R., Joh, Y. G., and Cho, M. Y. (2002). Effects of red ginseng upon postoperative immunity and survival in patients with state III gastric cancer. Am. J. Chin. Med. 30, 483-494.

Tawab, M. A., Bahr, U., Karas, M., Wurglics, M., and Schubert-Zsilavecz, M. (2003). Degradation of ginsenosides in humans after oral administration. Drug Metab. Dispos. 31, 1065-1071.

Wang, A. B., Wang, C. Z., Wu, J. A., Osinski, J., and Yuan, C. S. (2005). Determination of major ginsenosides in Panax quinquefolius (American ginseng) using high-performance liquid chromatography. Phytochem. Anal. 16, 272-277.

Wang, C. Z, Aung, H. H., Ni, M., Wu, J. A., Tong, R., Wicks, S., He, T. C., and Yuan, C. S. (2007a). Red American ginseng: ginsenoside constituents and antiproliferative activities of heat-processed Panax quinquefolius roots. Planta Med. 73, 669-674.

Wang, W., Zhao, Y., Rayburn, E. R., Hill, D. L., Wang, H., Zhang, R. (2007b). In vitro anti-cancer activity and structure-activity relationships of natural products isolated from fruits of Panax ginseng. Cancer Chemother. Pharmacol. 59, 589-601.

Wang, C. Z., Li, X. L., Wang, Q. F., Mehendale, S. R., Fishbein, A. B., Han, A. H., Sun, S., and Yuan, C. S. (2009a). The mitochondrial pathway is involved in American ginsenginduced apoptosis of SW-480 colon cancer cells. Oncol. Rep. 21, 577-584.
Wang, W., Rayburn, E. R., Hang, J., Zhao, Y., Wang, H., and Zhang, R. (2009b). Anti-lung cancer effects of novel ginsenoside 25-OCH (3)-PPD. Lung Cancer 65, 306-331.

Wang, W., Rayburn, E. R., Zhao, Y., Wang, H., and Zhang, R. (2009c). Novel ginsenosides 25-OHPPD and 25-OCH3-PPD as experimental therapy for pancreatic cancer: anticancer activity and mechanisms of action. Cancer Lett. 278, 241-248.

Wang, X., Zheng, Y. L., Li, K., Lin, N., and Fan, Q. X. (2009d). The effects of ginsenosides $\operatorname{Rg} 3$ on the expressions of VEGF and KDR in human lung squamous cancer cells. Zhong Yao Cai 32, 1708-1710.

Wang, W., Rayburn, E. R., Hao, M., Zhao, Y., Hill, D. L., Zhang, R., and Wang, H. (2008a). Experimental therapy of prostate cancer with novel natural product anti-cancer ginsenosides. Prostate 68, 809-819.

Wang, W., Wang, H., Rayburn, E. R., Zhao, Y., Hill, D. L., and Zhang, R. (2008b). 20(S)-25-methoxyldammarane-3beta, 12beta, 20-triol, a novel natural product for prostate cancer therapy: activity in vitro and in vivo and mechanisms of action. Br. J. Cancer 98, 792-802.

Wong, V. K., Cheung, S. S., Li, T., Jiang, Z. H., Wang, J. R., Dong, H., Yi, X. Q., Zhou, H., and Liu, L. (2010). Asian ginseng extract inhibits in vitro and in vivo growth of mouse lewis lung carcinoma via modulation of ERKp53 and NF- $\mathrm{B}$ signaling. J. Cell. Biochem. 111, 899-910.

Wu, C. F., Bi, X. L., Yang, J. Y., Zhan, J. Y., Dong, Y. X., Wang, J. H., Wang, J. M., Zhang, R., and Li, X. (2007). Differential effects of ginsenosides on NO and TNF-alpha production by LPS-activated $\mathrm{N} 9$ microglia. Int. Immunopharmacol. 7, 313-320.

Xia, L. J., and Han, R. (1996). Differentiation of B16 melanoma cells induced by ginsenoside RH2. Yao Xue Xue Bao 31, 742-745.

Xie, J. T., Wang, C. Z., Zhang, B., Mehendale, S. R., Li, X. L., Sun, S., Han, A. H., Du, W., He, T. C., Yuan, C. S. (2009). In vitro and in vivo anticancer effects of
American ginseng berry: exploring representative compounds. Biol. Pharm. Bull. 32, 1552-1558.

Xu, T. M., Cui, M. H., Xin, Y., Gu, L. P., Jiang, X., Su, M. M., Wang, D. D. and Wang, W. J. (2008). Inhibitory effect of ginsenoside $\mathrm{Rg} 3$ on ovarian cancer metastasis. Chin. Med. J. 121, 1394-1397.

Xu, T. M., Xin, Y., Cui, M. H., Jiang, X., and Gu, L. P. (2007). Inhibitory effect of ginsenoside $\mathrm{Rg} 3$ combined with cyclophosphamide on growth and angiogenesis of ovarian cancer. Chin. Med. J. 120, 584-588.

Yang, Z. G., Sun, H. X., and Ye, Y. P. (2006). Ginsenoside Rd from Panax notoginseng is cytotoxic towards HeLa cancer cells and induces apoptosis. Chem. Biodivers. 3, 187-197.

Yi, J. S., Choo, H. J., Cho, B. R., Kim, H. M., Kim, Y. N., Ham, Y. M., and Ko, Y. G. (2009). Ginsenoside $\mathrm{Rh} 2$ induces ligand-independent Fas activation via lipid raft disruption. Biochem. Biophys. Res. Commun. 385, 154-159.

Yoo, H. H., Yokozawa, T., Satoh, A., Kang, K. S., and Kim, H. Y. (2006). Effects of ginseng on the proliferation of human lung fibroblasts. Am. J. Chin. Med. 34, 137-146.

Yoon, J. H., Choi, Y. J., Cha, S. W., and Lee, S. G. (2012). Antimetastatic effects of ginsenoside Rd via inactivation of MAPK signaling and induction of focal adhesion formation. Phytomedicine 19, 284-292.

Yu, Y., Zhou, Q., Hang, Y., Bu, X., and Jia, W. (2007). Antiestrogenic effect of 20S-protopanaxadiol and its synergy with tamoxifen on breast cancer cells. Cancer 109, 2374-2382.

Yue, P. Y., Wong, D. Y, Wu, P. K., Leung, P. Y., Mak, N. K., Yeung, H. W. Liu, L., Cai, Z., Jiang, Z. H., Fan, T. P., and Wong, R. N. (2006). The angiosuppressive effects of 20(R)ginsenoside $\operatorname{Rg}(3)$. Biochem. Pharmacol. 72, 437-445.

Yun, T. K. (2001). Brief introduction of Panax ginseng C. A. Meyer. J. Korean Med. Sci. 16, 53-55.

Yun, T. K., and Choi, S. Y. (1990). A casecontrol study of ginseng intake and cancer. Int. J. Epidemiol. 19, 871-876.
Yun, T. K., and Choi, S. Y. (1998). Nonorgan specific cancer prevention of ginseng: a prospective study in Korea. Int. J. Epidemiol. 27, 359-364.

Yun, T. K., Yue, Y., and Han, I. W. (1983). Anticarcinogenic effect of long-term oral administration of red ginseng on newborn mice exposed to various chemical carcinogens. Cancer Detect. Prev. 6, 515-525.

Yun, T. K., Zheng, S., Choi, S. Y., Cai, S. R., Lee, Y. S., Liu, Y. X., Cho, K. J., and Park, K. Y. (2010). Nonorgan-specific preventive effect of long-term administration of Korean red ginseng extract on incidence of human cancers. J. Med. Food 13, 489-494.

Zhang, D., Yasuda, T., Yu, Y., Zheng, P., Kawabata, T., Ma, Y., and Okada, S. (1996). Ginseng extract scavenges hydroxyl radical and protects unsaturated fatty acids from decomposition caused by iron-mediated lipid peroxidation. Free Radic. Biol. Med. 20, 145-150.

Conflict of Interest Statement: The authors declare that the research was conducted in the absence of any commercial or financial relationships that could be construed as a potential conflict of interest.

Received: 24 January 2012; accepted: 11 February 2012; published online: $28 \mathrm{Feb}$ ruary 2012.

Citation: Nag SA, Qin J-J, Wang W, Wang $M-H$, Wang $H$ and Zhang $R$ (2012) Ginsenosides as anticancer agents: in vitro and in vivo activities, structureactivity relationships, and molecular mechanisms of action. Front. Pharmacol. 3:25. doi: 10.3389/fphar.2012.00025

This article was submitted to Frontiers in Ethnopharmacology, a specialty of Frontiers in Pharmacology.

Copyright (C) 2012 Nag, Qin, Wang, Wang, Wang and Zhang. This is an open-access article distributed under the terms of the Creative Commons Attribution Non Commercial License, which permits non-commercial use, distribution, and reproduction in other forums, provided the original authors and source are credited. 